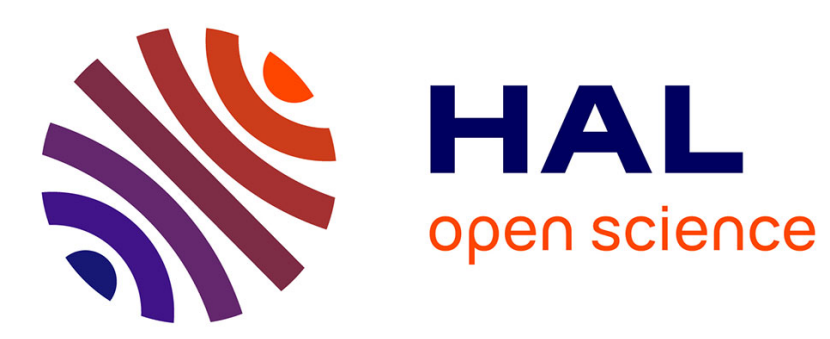

\title{
EXPERIMENTAL DUOPOLIES UNDER PRICE GUARANTEES
}

Gerardo Sabater, Nikolaos Georgantzis, Enrique Fatas, Mañez Castillejo Juan

\section{To cite this version:}

Gerardo Sabater, Nikolaos Georgantzis, Enrique Fatas, Mañez Castillejo Juan. EXPERIMENTAL DUOPOLIES UNDER PRICE GUARANTEES. Applied Economics, 2011, 45 (01), pp.15-35. 10.1080/00036846.2011.568398 . hal-00732113

\section{HAL Id: hal-00732113 https://hal.science/hal-00732113}

Submitted on 14 Sep 2012

HAL is a multi-disciplinary open access archive for the deposit and dissemination of scientific research documents, whether they are published or not. The documents may come from teaching and research institutions in France or abroad, or from public or private research centers.
L'archive ouverte pluridisciplinaire HAL, est destinée au dépôt et à la diffusion de documents scientifiques de niveau recherche, publiés ou non, émanant des établissements d'enseignement et de recherche français ou étrangers, des laboratoires publics ou privés. 


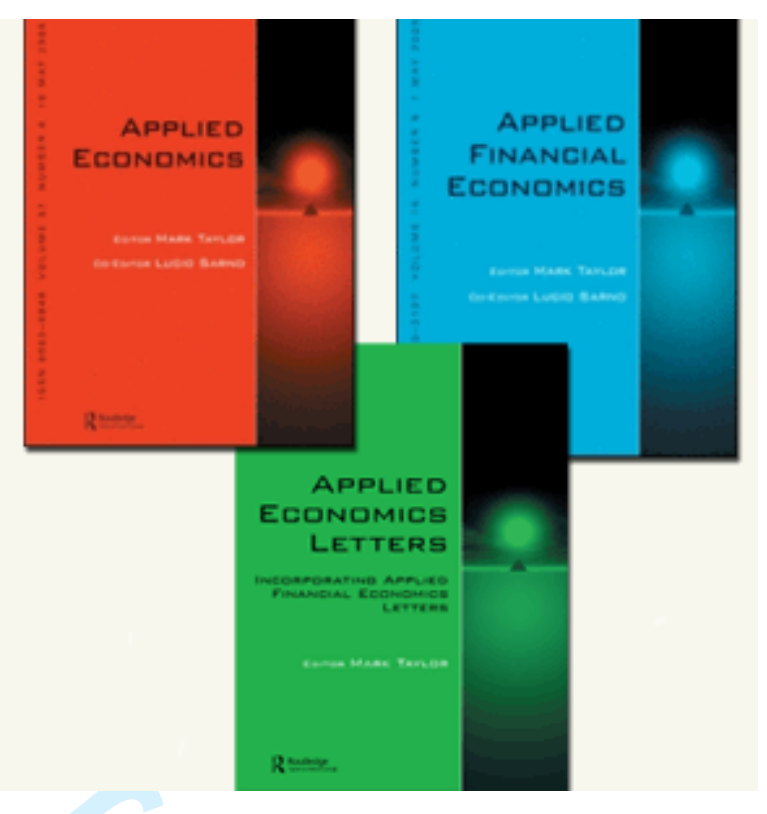

\section{EXPERIMENTAL DUOPOLIES UNDER PRICE GUARANTEES}

\begin{tabular}{|c|c|}
\hline Journal: & Applied Economics \\
\hline Manuscript ID: & APE-2009-0170.R1 \\
\hline Journal Selection: & Applied Economics \\
\hline $\begin{array}{r}\text { Date Submitted by the } \\
\text { Author: }\end{array}$ & 20-Jul-2010 \\
\hline Complete List of Authors: & $\begin{array}{l}\text { Sabater, Gerardo; University Jaume I, Economics } \\
\text { Georgantzis, Nikolaos; Universidad de Granada, Economics } \\
\text { Fatas, Enrique; EUniversity of valencia, LINEEX } \\
\text { Juan, Mañez Castillejo; Universidad de Valencia, Economia Aplicada } \\
\text { II }\end{array}$ \\
\hline JEL Code: & $\begin{array}{l}\text { C91 - Laboratory, Individual Behavior < C9 - Design of Experiments } \\
<\text { C - Mathematical and Quantitative Methods, L11 - Production, } \\
\text { Pricing, and Market Structure|Size Distribution of Firms }<\text { L1 - } \\
\text { Market Structure, Firm Strategy, and Market Performance < L - } \\
\text { Industrial Organization }\end{array}$ \\
\hline Keywords: & price guarantees, experimental duopolies, product differentiation \\
\hline
\end{tabular}




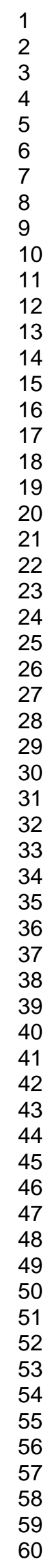

\section{SCHOLARONE ${ }^{m}$ \\ Manuscripts}

7

21

23

24

26

27

29

30

32

33

34

36

37

38

41

42

43

45

46

47

48

49

51

52

53

54

55

57

58

59

60 


\title{
Experimental Duopolies under Price Guarantees
}

\author{
Enrique Fatás ${ }^{1}$, Nikolaos Georgantzís ${ }^{2}$, Juan A. Máñez ${ }^{3}$ and Gerardo \\ Sabater4
}

\begin{abstract}
In a symmetric differentiated experimental duopoly we test the ability of Price Guarantees (PGs) to raise prices above the competitive levels. Different types of PGs ("aggressive" and "soft" price-beating and price-matching) are implemented either as an exogenously imposed market rule or as a business strategy. Our results show that PGs may lead close to the collusive outcome, depending on whether the interaction between duopolists is repeated and provided that the guarantee is not of the "aggressive" price-beating type.
\end{abstract}

Keywords: price guarantees, experimental duopolies, product differentiation JEL Classification: C91, L11

${ }^{1}$ LINEEX and University of Valencia (Spain), Enrique.Fatas@uv.es

2GLOBE and Economics Department, Universidad de Granada (Spain), ngeorgantzis@ugr.es.

${ }^{3}$ LINEEX and Department of Applied Economics II, University of Valencia (Spain), jamc@uv.es

${ }^{4}$ LINEEX, LEE and Department of Economics, University Jaume I, Av. de Vicent Sos Baynat, s/n.

12071 Castellón (Spain), sabater@eco.uji.es, , corresponding author. 


\section{Introduction}

A firm's commitment to offer its product at the lowest price in the market has inspired a large number of theoretical articles aiming at policy relevant recommendations. An interesting element of low-price guarantees is that they implicitly confirm a recurring assumption of theoretical IO models: when deciding on their strategies, firms account for their rivals' actions and reactions in a process which can be affected by strategic commitments to match or beat rival prices in the market. The former of these commitments, called Price Matching guarantees (PMG), consists of a public announcement by a firm to match the lowest price in the market, whereas the latter, Price Beating guarantees (PBG), corresponds to a promise to beat the lowest price in the market by a certain margin. Depending on the magnitude of the price-beating margin, we will refer to soft and aggressive price beating policies which is a central issue addressed in this paper. Both types of commitments, PMG and PBG have received some attention in the literature as separate phenomena, but they have not been sufficiently analyzed as a unified field of research so far. ${ }^{5}$

There are hundreds of examples of low price guarantees in several industries, like banking and retail products. Home Depot and Lowe's -retailers of home improvement and construction products and services- and Sears -an American chain of department stores- promise to reimburse the difference from the lowest price plus an extra $10 \%$ of the difference in return to a consumer's "kindness" to bring into the firm's attention the existence of a lower price for a similar product in the market. Target and Walmart, chains of discount department stores, promise to match lower

\footnotetext{
${ }^{5}$ Deck and Wilson (2003) have studied a general family of algorithms based on the comparison of prices across firms, without explicitly linking their paper to price matching and price beating. More recently, a growing literature deals with the related topic of pricing under specific strategic commitments, some of which aim at signaling as a complement or substitute of advertising. See, for example, Huang et al. (2010). Although this suggests that a more general approach to this type of commitments is necessary, here we restrict our attention to two specific competitor-based pricing commitments, leaving a more general approach for future research.
} 
competitor prices. The service $1^{\text {st }}$ American card guarantees to beat any published legitimate offer from a Visa/Mastercard Registered sales group or bank.

Most studies dealing with price guarantees opt for an in depth analysis of a very specific guarantee in a precisely defined market setting. Theoretical models treating each guarantee type separately from other types yield a fragmented view of the effects that such business strategies may have on the market outcome. The same deficit applies to empirical studies focusing on one or the other type of guarantee in isolation from other similar alternatives. One of the reasons is probably that the actual effects of these practices are difficult to empirically isolate and prove without a precise common benchmark corresponding to the price level that would have been in place under a more competitive environment. This makes the experimental laboratory a convenient environment for determining which market conditions facilitate the emergence of supra-competitive prices.

To the best of our knowledge, a unified analysis of a broad variety of price guarantees under different market conditions has never been implemented in the laboratory. In this paper, we report results from experiments aimed at a systematic study of alternative price guarantees in the framework of experimental differentiated oligopolies, in which firms are represented by human subjects. We unify the analysis reported in our previous papers and extend it by introducing the case of soft price beating, which lies between the extremes of price matching (analyzed in Fatas and Mañez (2007)) and aggressive price beating (studied in Fatas et al. (2005)). The new evidence suggests that the difference between the two types of guarantees depends on the aggressiveness of price beating. For every treatment, we control for the impact of reputation and repeated interaction between firms, using two different matching protocols ("strangers" and "partners"), implying two different levels of difficulty for the emergence of tacitly collusive outcomes. In addition, for every treatment and 
every matching procedure, two alternative policy scenarios are examined. Contrary to the design of Deck and Wilson (2003) whose subjects were offered a variety of pricing policies (none of which coincides with the price beating guarantees used here), our design permits a specific comparison of different market environments, by distinguishing between industry wide (exogenous) and firm-specific (endogenous) adoption of price guarantees. The two control designs are compared to each other and each one of them to a baseline set-up in which no price guarantee commitment is available. In this way, we obtain sufficient evidence on markets in which price guarantee is totally absent (baseline treatment), globally present (market institution treatment) and voluntarily adopted by the subjects (business strategy treatment). Therefore, data availability on different combinations of prices and pricing policies do not exclusively depend on the observed adoption rates.

Our results strongly suggest that the market price consequences of price guarantees appear to be extremely sensitive to the aggressiveness of the price policy. That is, whether the firm adopting the guarantee promises to beat rival prices by a small margin or by a large one. Specifically, we find that in the presence of aggressive PBG effective prices remain close or even below non cooperative (Bertrand) levels. On the contrary, soft PBG yield prices which are similar to those obtained under price matching guarantees (PMG). Therefore, a per se treatment of price beating guarantees is not necessary, because committing on a sufficiently drastic undercutting makes the adoption of PBG a precompetitive market strategy.

The remaining part of the paper is structured as follows: Section 2 reviews the existing literature on price guarantees; Section 3 describes the experimental design; the results are analyzed and discussed in Section 4 and Section 5 concludes. 


\section{Related Literature}

Despite the apparent pro-competitive nature of a firm's willingness to offer the best price in the market, since Stigler's (1964) early work on oligopoly, it has been recognized that the practice of matching or beating any rival's price in a market may have anti-competitive effects, although a case by case approach is usually recommended to antitrust authorities ${ }^{6}$. However, the debate on whether low-price guarantees (PGs, hereafter) facilitate tacit collusion was triggered by Salop (1986). Thereafter, the anti-competitive effects of PGs have been studied in different frameworks. Regarding PMGs, Doyle (1988) analyzes a homogenous Bertrand oligopoly game concluding that collusion is possible if all sellers adopt price matching strategies. Similar results are obtained by Logan and Lutter (1989) in a differentiated duopoly model and by Chen (1995), assuming that firms commit to price guarantee policies before they choose their prices.

Concerning the difference between PMG and PBG, Dixit and Nalebuff (1991), Sargent (1993) and Baye and Kovenock (1994) conclude that price-beating guarantees are even more effective than price-matching guarantees at supporting higher prices. On the basis of these analyses, they claim antitrust actions should be taken against this class of guarantees. However, more recent papers have argued in the opposite direction. Hviid and Shaffer (1994) and Corts (1995) suggest that if firms can promise to beat as well as match posted prices, the Bertrand intuition may reemerge as firms can capture the entire market by profitable undercutting. In related work, Hviid and Shaffer (1999) assume that there is a cost borne by the consumers claiming the promised re-imbursement. They show that the existence of such a hassle cost is sufficient to limit the ability of price guarantees to support supra-competitive prices. On the other hand, Doyle (1988), Edlin (1997) and Kaplan (2000) show that

\footnotetext{
${ }^{6}$ As a result, such guarantees are not treated as illegal per se by either European or US legislation.
} 
monopoly pricing is restored if both final and posted prices can be matched or beaten, an assumption which better fits with the spirit of guaranteed lowest prices.

The relevant empirical work for price guarantees is heterogeneous in both the approach and the results obtained. In an analysis of conventional supermarket price setting Hess and Gerstner (1991) document the anticompetitive effects of a pricematching guarantee. Similar results are obtained by Smith et al. (1999) and Corts for digital markets (1997). Contrary to this evidence and using a sample of prices for alcoholic beverages, Milyo and Waldfogel (1999) find that price-matching stores' prices are significantly lower. Additionally, Arbatskaya, et al. (2004) study the effects of various kinds of price guarantees on advertised prices using retail tire prices collected from U.S. Sunday newspapers ${ }^{7}$. They conclude that PMGs and PBGs do not have any effect on firms' own prices, although they point out that this result could be due to firm, market or guarantee-type heterogeneity.

Chen and Liu (2007a) study the impact of a policy change on price competition among electronic products sold by major online retailers, finding that the policy change leads to greater disparity in prices. Using a similar sample of data, Chen and Liu (2007b) find that less restrictive PGs actually facilitate high prices.

Finally, Mañez (2006) and Lundberg (2008) investigate PGs in UK food retailing and the Swedish electronics market, respectively. Their results point out to the use of low price guarantees as advertising devices to signal low-prices.

There are a relatively small number of experiments dealing with the effects of price guarantees on the market outcome. In a different setup to ours', Jain and Srivastava (2000) analyze how consumers view and interpret price guarantees, assuming a theoretical framework of price discrimination between informed and

\footnotetext{
${ }^{7}$ Using this evidence Arbatskaya, et al. (2006) find that the majority of paired observations involving firms that have PMG (PBG) are (not) consistent with what one would expect if firms were using them to discourage price cutting. This suggests that PMG and PBG may be serving different purposes.
} 
uninformed consumers. ${ }^{8}$ However, subjects were asked to submit responses to a hypothetical questionnaire. Additionally, the paper focuses on the effect of PMGs on the buyers' quality perception of stores. Deck and Wilson (2003) is the first experiment with monetary rewards on an issue related to price guarantees. They simultaneously test the impact of an assorted variety of price guarantees and pricing algorithms, when firms can track customers' search behavior ${ }^{9}$ to find that they may act for sellers as a device to manage internet competitive pressures. Their results show that, contrary to price matching, price beating or trigger strategies lead prices near (or below, in the case of the latter) the static Nash equilibrium prediction. ${ }^{10}$

Moorthy and Winter (2006) examine the incentives for PMG in markets where information about prices is costly. These authors conclude that price-matching guarantees may be a credible mean of communicating to uninformed consumers that a firm is low priced, supporting the signaling theory. In this sense, Dugar and Sorensen (2006) investigate the collusion-facilitating nature of price-matching guarantees, testing the theoretical prediction of Hviid and Shaffer (1999) along with the predictions from the three stylized market models that permit varying proportions of positive and zero ${ }^{11}$ hassle cost buyers in the market.

Additionally, Dugar (2007) tests the collusive theory of PMGs in the Bertrand homogenous product setting and try to provide evidence regarding the equilibrium selection from a set of Pareto-rankable equilibria for the PMG model. The experimental evidence supports the theoretical prediction that these guarantees yield collusive behavior among sellers. Regarding the multiplicity of equilibria, this study

\footnotetext{
8 See Srivastava (2001), Srivastava and Lurie (2004) and Lurie and Srivastava (2005) for parallel analyses.

${ }^{9}$ See Gwin and VanHoose (2010) exploring the relationship among consumer search costs, the relative degree of price stickiness and firm markups.

10 The puzzling result that most subjects kept on offering the non profitable undercutting guarantee and abandoning the profitable price matching one seems to be context dependant: subjects simultaneously choose the extent of the different guarantees.

${ }^{11}$ Dugar (2005) confirms the predicted collusive effects of PMGs in the absence of hassle costs.
} 
found considerable evidence of coordination success for the particular subgame where all the sellers adopt PMGs.

Introducing markets with cost asymmetries, Mago and Pate (2009) find that the ability of price matching guarantees to act as a collusion facilitating device becomes contingent on the relative cost difference and suggesting that the mere presence of cost asymmetries may curtail collusive behavior. Unlike us, they introduce the presence of cost asymmetries between sellers, employing a homogenous goods environment, where quantity is determined in the usual discontinuous manner, given that the lowest priced seller serves the entire demand. Contrary to Dugar (2007) and similar to our approach, they recognize the strategic nature of such guarantees as a long run commitment, allowing the price matching option to be available every four periods, while the pricing decision is made every period. Despite the aforementioned differences, we obtain similar results concerning the collusion facilitating role of price matching.

Fatas et al. (2005) study aggressive PBG in a price-setting duopoly and find that, although in most cases the availability of PBGs leads to higher posted prices, effective prices remain close or even below non cooperative (Bertrand) levels. Also, adoption levels below 50\% are reported, which contrasts with Deck and Wilson's (2003) result of pervasive guarantee adoption. In a similar setup, Fatas and Mañez (2007) find that Bertrand competition between symmetric firms with a differentiated good is intensely altered by the introduction of PMG, as equilibria with prices higher than the ones corresponding to the Bertrand-Nash equilibrium emerge. Our results about high price matching adoption rates are consistent with other studies like Mago and Pate (2009) and Dugar (2007). Moreover, the market effect of price guarantees depends on their specific features in line with Hviid and Shaffer (1999). 


\section{Experimental design}

We consider a price-setting duopoly in which two firms ( $i$ and $j$ ) choose a posted price $\left(p_{i}^{p}, p_{j}^{p}\right)$ and a price $\operatorname{policy}\left(\delta_{i}, \delta_{j}\right) \quad:$

$$
\delta_{i}=\left\{\begin{array}{c}
N P G=N o \text { Price Guarantee } \\
P G=\text { Price } \text { Guarantee }
\end{array}\right.
$$

Let the effective price of firm $i$ under each one of these strategies be:

$$
p_{i}^{e}=\left\{\begin{array}{l}
p_{i}^{p} \quad \text { if } \quad \delta_{i}=N P G \\
p_{i}^{p}-\alpha\left(p_{i}^{p}-\min \left\{p_{i}^{p}, p_{j}^{p}\right\}\right) \quad \text { if } \quad \delta_{i}=P G
\end{array}\right.
$$

In the second part of (2), the parameter $\alpha$ denotes the reduction in own posted price promised by a firm adopting a guarantee as a reaction to a lower rival price. The parameter implies a continuum of guarantees ranging from price matching $(\alpha=1)$ to different levels of price beating $(\alpha>1)$. Then, the higher the value of $\alpha$ is, the fiercer is the undercutting announced by the firm adopting the guarantee. For example, a "double-the-difference" guarantee corresponds to $\alpha=2$. Each one of two firms, $i$ and $j$, sells one of the two varieties of a differentiated product, knowing that the demand for each variety is given by:

$$
q_{i}=V-\beta p_{i}^{e}+\not p_{j}^{e}
$$

$V$ is the demand intercept, while $-\beta$ and $\gamma$ represent, respectively, the derivatives of the demand with respect to own and rival prices. The unit (marginal, average) cost of 
production, $c$, is constant and equal for both firms. Therefore, the profits of firm $i$ are given by:

$\Pi_{i}=\left(p_{i}^{e}-c\right) q_{i}$.

For the sake of clarity, we denote the following benchmark solutions as follows:

1. The Bertrand Nash Equilibrium (BNE) of the one-shot game, satisfying the first order conditions: $\frac{\partial \Pi_{i}}{\partial p_{i}}=0$ and $\frac{\partial \Pi_{j}}{\partial p_{j}}=0$

2. The Collusive solution (CS), satisfying the first order conditions: $\frac{\partial \Pi}{\partial p}=0$, where $\Pi=\Pi_{i}+\Pi j$ and $p=p_{i}=p_{j}$

In order to study the effect of PGs on prices, we consider twelve different treatments. In all treatments, two firms (each represented by an experimental subject) offer two varieties of a differentiated good during 50 rounds. In the baseline treatments (BSL) subjects decide on posted (thus, effective) prices only. PG were introduced in all other treatments using two different Implementation Rules (IR): first, PGs were exogenously imposed as an industry-wide institution (labelled as "Market rule" or "M"). Secondly, PGs were offered to the subjects as an option (labelled as "Business strategy" or "B"). In treatments using the second implementation rule, each firm's effective selling price depends both on own and rival posted prices as well as on the price-policy decisions. For each IR three positive values of the parameter $\alpha$ are analysed: $\alpha=1$ (PMG), $\alpha=1.1$ (soft-PBG) and $\alpha=2$ (aggressive-PBG). 
While for $\alpha>1$ the undercutting logic of Bertrand competition applies and there is a unique $\mathrm{BNE}$ ), for $\alpha=1$ there are multiple equilibria. When the PG are exogenously imposed (the so called "Market Rule"), a continuum of NE arise as any symmetric price from the Bertrand solution (BS) to the collusive solution (CS) is an equilibrium. ${ }^{12}$ When PG are implemented using a Business strategy it is always a NE for both firms to set the Bertrand price and not to adopt PMG. Again, if both firms offer PMG a continuum of NE emerges, from Bertrand to the collusive solution. ${ }^{13}$ On top, equilibrium effective prices are limited by the collusive price; unilateral price cutting, even if automatically matched by the rival, would result in higher profits. Analogously, equilibrium effective prices are bottom bounded by the Bertrand price, as any firm could obtain higher profits by increasing its posted price (with no PMG). There is even an additional equilibrium in which only one firm adopts PMG and both firms set the Bertrand price. ${ }^{14}$ We summarise the main testable hypotheses of our symmetric experimental model in Table 1.

Insert Table 1 here

Even when the Collusive Solution is an equilibrium in some of our treatments (whenever $\alpha=1$ ), it is far from obvious that subjects will be able to coordinate and collude. Van Huyck, Battalio and Beil (1990) is a seminal contribution where coordination critically depends on the structure of the game and the repeated interaction with the same opponent. ${ }^{15}$ Brandts and Cooper (2006) and Brandts,

\footnotetext{
${ }^{12}$ See Hviid and Shaffer (1999), proposition 1, for a proof of equilibria boundaries.

${ }^{13}$ In symmetric markets all firms must adopt PMG for prices to rise above the Bertrand price.

${ }^{14}$ Both firms cannot increase profits by setting a different price (or adopting PMG). See Proposition 1.B in Doyle (1988) and Fatas and Mañez (2006) for a complete theoretical analysis.

${ }^{15}$ In their Experiment $\mathrm{C}$, full coordination is reached more than half of the times when subjects repeatedly interact with the same opponent while it is never observed when interacting with a different one each round.
} 
Cooper and Fatas (2007) show that coordination failure tend to persist even in simple games.

The strategic complexity of our game is much greater than the usually observed in simple coordination games a la van Huyck et al. (1990). The main differences are the following: (i) our subjects have no information about the demand function, (ii) all salient solutions of our game are interior, (iii) our strategy space is a quasi-continuum, ${ }^{16}$ and (iv) subjects had never interacted before in previous experiments. ${ }^{17}$

To check for the robustness of the effects on market prices, we use two different matching mechanisms to control for the repeated interaction of subjects: strangers and partners. In the former (labelled as "S"), random pairs of subjects are formed in each round, whereas in the latter (labelled as "P") subject pairs forming duopolies are kept constant throughout the session. Obviously, the strangers protocol does not prevent subjects from being matched with the same opponent more than once along a session, but the probability is relatively low. Note that protocol "S" implies an extremely unfavorable environment for the emergence of collusion and provides a strong test for the hypothesis of anti-competitiveness of PGs. Analogously, the "P" protocol provides a strong test for the hypothesis of competitive behavior (given the results obtained in the case of price matching with the protocol "S", running more treatments under the "P" would be unnecessary). In addition to the set of hypotheses summarised in Table 1, we can make the following behavioural hypothesis: as coordination is easier with the partner protocol, we expect effective prices to be higher in the partners protocol sessions than in their strangers counterparts. Thus, the main objective of the strangers-vs-partners design is to

\footnotetext{
${ }^{16}$ It exactly includes 4710 different choices; while van Huyck et al. (1990) has only seven choices and Brandts and Cooper (2006) and Brandts et al. (2006) five.

${ }^{17}$ See Fatás et al. (2006) for a review of recent experimental results on coordination games.
} 
disentangle possible price increases due to reputation and repeated interaction from pure price-guarantee effects.

Table 2 presents all treatments with their corresponding design variables. For each treatment using a strangers matching protocol, we ran two experimental sessions, whereas for treatments with a partners protocol a single session was run. ${ }^{18}$ Given that PGs were introduced both as a market rule and a business strategy, we ran a total of 19 PGs sessions with 18 subjects each. A total of 342 subjects participated in the experiment.

Insert Table 2 here

The time structure of the game is as follows. In each round of BSL and M treatments, subjects decide independently and simultaneously the posted price of the variety they sell. At the end of each round, subjects receive feedback regarding own and (this round's) rival prices, demands and profits. A complete history of these results and the corresponding actions is also available to them. In BS, each firm decides both on its posted price and price policy, receiving additional information concerning the price-policy decision of the rival firm. In fact, firms decide their posted prices in every round, but they choose whether they adopt or not a given PG (depending on the treatment, PMG, aggressive-PBG, or soft-PBG) every five rounds. This design represents the fact that in the real world prices may be changed more often than pricing policies. Furthermore, this sequence of 5-period pricing subgames during which price policies are kept fixed allows subjects to "learn" the optimal price that corresponds to each combination of own and rival policies. Once the players' information is updated, a new round starts. Subjects are not aware of the

${ }^{18}$ From the 900 decisions (50 pricing decisions times 18 subjects) of each experimental session with a "S" protocol, we obtained a single independent observation. Thus, under this protocol we ran twice as many sessions as under a " $\mathrm{P}$ " protocol in which 18 independent observations were obtained per session. 
mathematical specification of the underlying demand model and have common information about the rules of the game.

Let us now describe how each one of the BSL, M and BS treatments instructions were explained to the subjects. In the Bertrand price setting game proposed in the BSL treatments, firms' posted prices were necessarily equal to their effective price. In the $\mathrm{M}$ treatments we impose PG as a market institution. Thus, subjects were informed that their effective price were always the lowest posted price. Whereas in the BSL and M treatments subjects choose just a posted price, in the BS treatments subjects have to choose a posted price and a price policy, so subjects could think of BS treatments as a case in which they played two different games: game A and game B. In game A, players simultaneously and independently choose a posted price and a price policy. In game B, subjects just have to decide about their posted price. Subjects play game A at the initial round and then every five rounds. In the rest of the rounds, subjects knew they had to play game B alone.

In Table 3, we present competitive and collusive equilibrium values for prices, demands and profits for the parameters used in the analysis: $V=730, \beta=1.5, \gamma=0.5$ and $c=30$. These parameter values were chosen so that theoretical predictions were not focal points in any way. Subjects could post any price between 30 (below-unitcost pricing was not allowed) and 1000 (including non-integer prices in steps of 0.1 monetary units) expressed in experimental currency units (ExCUs).

Insert Table 3 here

Inexperienced subjects were recruited among undergraduate students from different economics or business-related courses, using standard recruitment procedures at the University of Valencia. Before the beginning of each session, 
subjects were given written instructions, while the organizers read aloud the instructions and answered any remaining questions. ${ }^{19}$

At the end of each session, subjects were privately paid in cash. A typical session lasted 60-80 minutes (depending on the experimental treatment) and subjects obtained average earnings of about $18 €$. All sessions were computerized and carried out at the LINEEX ${ }^{20}$, using software based on the Z-Tree toolbox. ${ }^{21}$

\section{$4 \quad$ Experimental Results}

\subsection{Descriptive statistics and figures}

Table 4 presents a summary of our results from a purely descriptive perspective. It is a general feature of our results that, in all sessions, price dispersion decreases over time. In Table 3, we see that the standard deviation of prices is lower in the second half of a session than in the first half of it. ${ }^{22}$ This is the result of the learning process, due to which price strategies are volatile and noisy in the initial periods, whereas they get closer to and within the relevant equilibrium range towards the end of the experiment. In order to abstract from the issue of learning in a noisy feedback environment, we restrict most of our analysis to data obtained from the second half of each session.

Insert Table 4 here

\footnotetext{
19 The translated instructions are included in the appendix.

${ }^{20}$ Experimental Economics Laboratory at the University of Valencia.

21 Z-Tree was originally developed by Urs Fischbacher (2007) at the Institute for Empirical Research of Economics (University of Zürich).

22 Similar results are obtained (detailed results are available upon request) by regressing for each experimental session per-period standard deviation on a dummy variable that takes the value of 1 for the last twenty five rounds and 0 otherwise. All coefficients estimated are negative and significant (depending on the treatments, they range between -21.9 and -94.2) indicating a lower dispersion of prices over time. As García-Gallego and Georgantzís (2001) point out, this is partly a consequence of subjects' lack of information about the true demand model, forcing them to randomly choose their initial price strategies which, following some try-and-error learning, get closer to the theoretical values as the session proceeds.
} 
Figures 1-6 show average per round prices (effective, in the case of $M$ and B treatments) for each value of the parameter $\alpha$ and IR under the two matching protocols (P and S). The Bertrand Nash Equilibrium (BNE, soft line) and Collusive Solution (CS, hard line) price levels are also provided.

Although the results obtained from formal econometric analysis are presented below, some preliminary observations are in order. Generally speaking, the BNE prediction seems to be a better predictor of average effective prices for all BSL and aggresive-PBG treatments. However, the CS is a better predictor for all PMG and soft-PBG treatments. For example, Figures 1 and 2 present the clearest and most stable patterns of convergence towards the non cooperative and collusive price levels respectively. Figure 3 reflects the only case in which prices persistently remain below the non cooperative equilibrium level. Finally, the remaining Figures 4, 5 and 6 present more volatile patterns of convergence near the non cooperative (figure 4) and the collusive (figures 5 and 6 ) equilibrium predictions. ${ }^{23}$

Insert Figures 1-6 here

\subsection{On price guarantee adoption}

Figures 7 to 11 present the percentage of subjects adopting the guarantee in each one of the periods in which the option is available (business strategy sessions). Also "entry" and "exit" results indicate the percentages of subjects changing from non-adoption to adoption (the former) and from adoption to non-adoption (the latter) across consecutive PG adoption-decision rounds.

${ }^{23}$ An alternative descriptive analysis is provided in Appendix II, with estimations of density functions for every treatment. 
For PMG, the exit rate (which presents a decreasing trend) is much lower than the entry rate which implies an increasing trend of PMG adoption rates. Furthermore, from the first adoption decision, the number of subjects adopting PMG is higher than the number of subjects that do not adopt. This is especially evident from round 36 on, as the number of subjects adopting is at least three times the number of subjects non-adopting. This majoritarian rate of adoption seems to be compatible with the Nash equilibrium in which all firms adopt PMG and any symmetric price between the BNE and CS is an equilibrium (see Table 1).

As opposed to theory, we observe positive rates of adoption in any of the PBGs sessions. A deeper analysis reveals that whereas with soft PBG adoption is clearly a predominant strategy, with aggressive PBG there are not significant differences between the number of adopter and non-adopters (it is possible to observe in figures 10 and 11 that some adopting rounds the number of non-adopters outweighs that of adopters). ${ }^{24}$

Therefore, we can summarise our finding on price adoption in the following manner:

Result 1: When PMG is available, PMG adoption is the predominant choice.

Result 2: When PBG is available, we observe adoption by a significant share of the experimental subjects. However, there are remarkable differences between the rates of adoption with soft and aggressive PBG.

Insert Figures 7-11 here

\footnotetext{
24 The observed patterns of adoption of PBGs contrasts with excessively high and certainly counterintuitive percentages of adoption (over 90\%) obtained in Deck and Wilson (2003). Our control for the effects of endogenous guarantees indicates that the negative effects of PBG's on profits are perceived by the subjects and this is reflected on a low frequency of PBG adoption.
} 


\subsection{Comparison of effective prices}

To compare prices and profits across treatments, we estimate a model taking into account the 12 experimental treatments at the same time. We use panel data techniques to estimate a random effects model using the following reduced form equation:

$$
\begin{aligned}
& s_{i t}=\beta_{0}+\beta_{1} D_{P M B}+\beta_{2} D_{P M M}+\beta_{3} D_{P B 1 B}+\beta_{4} D_{P B 1 M}+\beta_{5} D_{P B 2 B}+\beta_{6} D_{P B 2 M}+\beta_{7} D_{P}+ \\
& +\beta_{8} D_{P} D_{P B 1 B}+\beta_{9} D_{P} D_{P B 1 M}+\beta_{10} D_{P} D_{P B 2 B}+\beta_{11} D_{P} D_{P B 2 M}+\mu_{i t}
\end{aligned}
$$

where the endogenous variable, $\mathrm{s}_{\mathrm{i}}$, is effective price or profit of firm $i$ in period $t$ (for $t=26, \ldots, 50)$. $\mathrm{D}_{\mathrm{PMB}}$ is a dummy variable set equal to one for prices (profits) of the experimental sessions in which PMG is a business strategy and $\mathrm{D}_{\mathrm{PMM}}$ is a dummy variable set equal to one for prices (profits) of the sessions in which PMG is a market rule. Analogously, $\mathrm{D}_{\mathrm{PBiB}}$ and $\mathrm{D}_{\mathrm{PBiM}}($ for $i=1,2)$ are dummy variables set equal to one for prices of the experimental sessions in which PBiG is a business strategy and a market institution, respectively. Finally, $\mu_{i t}=\alpha_{i}+\varepsilon_{i t}$ where $\alpha_{i}$ are the individual effects that are considered as random effects, and $\varepsilon_{\mathrm{it}}$ is the error term.

By construction, $\beta_{0}$ is the mean price for the BSL sessions in which subjects are matched using a strangers protocol and $\beta_{7}$ is the average variation to this price (profit) due to the change from a strangers to a partner protocol. Further, $\beta_{1}$ and $\beta_{2}$ are the average price differentials between PMB and BSL $\left(\Delta_{\mathrm{S}}^{P M B / B S L}\right)$ and PMM and $\operatorname{BSL}\left(\Delta_{\mathrm{S}}^{P M M / B S L}\right)$ when subjects are matched using a strangers protocol. ${ }^{25}$

${ }^{25}$ Table A1 in the Appendix shows how to obtain estimated average prices from the estimation of equation (5). We obtain estimated price differentials using these estimated average prices. 
$\beta_{3}\left(\beta_{5}\right)$ and $\beta_{4} \quad\left(\beta_{6}\right)$ are the average price differentials between PB1B (PB2B)/BSL and PB1M (PB2M)/BSL when subjects are matched using a strangers $\operatorname{protocol}\left(\beta_{3}=\Delta_{\mathrm{S}}^{P B 1 B / B S L}, \beta_{4}=\Delta_{\mathrm{S}}^{P B 1 M / B S L}, \beta_{5}=\Delta_{\mathrm{S}}^{P B 2 B / B S L}\right.$ and $\left.\beta_{6}=\Delta_{\mathrm{S}}^{P B 2 M / B S L}\right)$. Analogously, $\beta_{3}$ $+\beta_{8}\left(\beta_{5}+\beta_{10}\right)$ and $\beta_{4}+\beta_{9}\left(\beta_{6}+\beta_{11}\right)$ are the average price differentials PB1G-B/BSL (PB2G-B/BSL) and PB1G-M/BSL (PB2G-M/BSL), for partner sessions. $\left(\beta_{3}+\beta_{8}=\Delta_{P}^{P B 1 B / B S L}, \beta_{4}+\beta_{9}=\Delta_{P}^{P B 1 M / B S L}, \beta_{5}+\beta_{10}=\Delta_{P}^{P B 2 B / B S L}\right.$ and $\left.\beta_{6}+\beta_{11}=\Delta_{P}^{P B 2 M / B S L}\right)$.

For the BSL sessions the average price differentials between the partner and the strangers protocol sessions is $\beta_{7}\left(\Delta_{P / S}^{B S L}\right)$. The average price variations of $\mathrm{PB} 1 \mathrm{~B}$ and PB1M prices due to the change from a strangers to a partners protocol $\left(\Delta_{P / S}^{P B 1 B}\right.$ and $\left.\Delta_{P / S}^{P B 1 M}\right)$ are $\left(\beta_{7}+\beta_{8}\right)$ and $\left(\beta_{7}+\beta_{9}\right)$, respectively. Analogously, the average price variations of $\mathrm{PB} 2 \mathrm{~B}$ and $\mathrm{PB} 2 \mathrm{M}$ prices when changing from a strangers to a partners $\operatorname{protocol}\left(\Delta_{P / S}^{P B 2 B}\right.$ and $\left.\Delta_{P / S}^{P B 2 M}\right)$ are $\left(\beta_{7}+\beta_{10}\right)$ and $\left(\beta_{7}+\beta_{11}\right)$.

The panel data estimates ${ }^{26}$ of (5) for effective prices and are shown in Table 5. To facilitate interpretation, next to each variable (in parentheses) we provide, when it is the case, the estimated average price differential. Thus, for example the coefficient of $D_{p}$ is an estimate of $\Delta_{P / S}^{B S L}$. In Table 5 we show the $\chi^{2}(1)$ tests comparing each one of the estimated average prices both to the BNE and CS price.

The estimates indicate that the average effective price in the baseline sessions in which subjects are matched using a strangers protocol (289.10) is significantly below the Bertrand-Nash prediction (see Tables 5 and 6). However, average effective

\footnotetext{
${ }^{26}$ In this case there is no difference between the estimates of the fixed and random effects models. The reason is that given the way we have constructed all the independent variables they do not show any between-groups variation (in this case each experimental subject is a group). Note that fixed effects model estimates are obtained from the within-group estimator whereas random effects model estimates are a weighted average of the within and between-group estimators. Thus, if there is no between-group variation, the estimates of both models are identical.
} 
price in the partner session in which a PBG is not available (331.22) is not significantly different from the one corresponding to the Bertrand-Nash prediction.

Insert Table 5 here

The introduction of PMG either as a market rule or as business strategy results in average effective prices that are significantly higher than those obtained when no guarantee is available, as both $\Delta^{P M B / B S L}$ and $\Delta^{P M M / B S L}$ are positive and significant $\left(74.79\right.$ and 90.90 , respectively). ${ }^{27}$ Further, the average price increase produced by PMG as a market rule is significantly higher than the one produced by PMG as a business strategy. Neither the PMB nor the PMM average prices are significantly different to the CS price (see Table 5). Therefore, we can state the following result.

Result 3: The introduction of PMG (either as a market rule or as business strategy) in the space relevant alternatives results in higher effective prices.

As for PMG, the joint consideration of Results 1 and 3 is evidence in favour of anti-competitive effects of PMG: subjects predominantly adopt PMG with the result of prices above the competitive ones (i.e. the effective prices when no guarantee is available). This experimental evidence closely resembles the NE in which all firms and prices raises up to collusion levels (see Table 1).

Insert table 6 here

As opposed to theoretical predictions, our estimates reveal that the effects of PBGs on effective prices critically depend on the aggressiveness of the PBG. Regardless of the matching protocol, the introduction of an aggressive "double-the-

27 At a conventional 5\% significance level. 
difference" PBG (PB2, i.e. $\alpha=2$ in equation 2) either as a market rule or as a business strategy does not result in average effective prices significantly different from those obtained when no guarantee is available $\left(\Delta_{\mathrm{S}}^{P B 2 M / B S L}, \Delta_{\mathrm{S}}^{P B 2 B / B S L}, \Delta_{\mathrm{P}}^{P B 2 M / B S L}\right.$ and $\Delta_{\mathrm{P}}^{P B 2 B / B S L}$ are not significant).

The introduction of a soft-PBG (PB1G, i.e. $\alpha=1.1$ in equation 2 ) produces higher effective prices independently of the matching protocol. In the strangers protocol sessions, the average price increase caused by soft-PBG as business strategy $\left(\Delta_{\mathrm{S}}^{P B 1 B / B S L}\right)$ and a market institution $\left(\Delta_{\mathrm{S}}^{P B 1 M / B S L}\right)$ is 85.53 and 139.81 respectively. Further, the average price increase produced by the introduction of soft-PBG as a market rule is significantly higher than that due to the introduction of soft-PBG as a business strategy. As a result, while the average price in the sessions in which softPBG is a business strategy (374.63) is not significantly different to the CS price, the average effective price in the sessions in which soft PBG is a market rule (428.63) is significantly higher than the CS price (see Table 5).

In the partner sessions of soft-PBG the average price increase produced by the introduction of soft-PBG is independent of whether the guarantee is introduced as a market rule or a business strategy, as indicated by $\Delta_{\mathrm{P}}^{P B 1 G-B / B S L}(34.15)$ and $\Delta_{\mathrm{P}}^{P B 1 G-M / B S L}$ (49.46) which are not significantly different from each other. Additionally, both the average price in the sessions in which soft-PBG is a business strategy and a market rule are not significantly different from the CS price (see Table 5).

Therefore, our results on PBG can be summarised as follows:

Result 4: The effects of PBG on effective prices depend crucially on the aggressiveness of the guarantee.

Result 4.a: The introduction of soft PBG results in prices significantly higher than those without guarantees. 
Results 4.b: The introduction of aggressive PBG does not show any ability to raise prices above the prevailing prices without guarantees.

Result 4.a suggest that, contrary to theoretical predictions, soft PBG inherit the ability of PMG to raise prices. Furthermore, a substantial part of the experimental subjects adopting such soft PBG. As for Results 4.b., the lack of ability of aggressive PBG fits the theoretical prediction about prices PBG for symmetric duopolies. However, the theory predicts non-adoption and it appears that a non-negligible proportion of experimental individuals adopt aggressive PBGs.

As for our behavioural hypothesis, it is always that average prices in the partners protocol sessions are higher than in the corresponding strangers protocol sessions except in the case of soft PBG. ${ }^{28}$

Figure 12 summarises and ranks experimental average prices for each one of treatments taking into account the tests comparing average prices with the CS price and the BNE (shown in Table 6) and the pair-wise test used to test price differentials.

\subsection{Adoption posted prices and profits}

To look into the effect of price guarantees adoption on posted prices and profits in the sessions in which the price guarantee is a business strategy, we estimate a random effects model using the following reduced form equation:

$$
s_{i t}=\beta_{0}+\beta_{1} D_{A}+\beta_{2} D_{P}+\beta_{3} D_{A} D_{P}+\mu_{i t}
$$

In equation (6) $s_{i \text {, }}$ is posted price or profit of subject $i$ in period $t$ (for $t=26, \ldots, 50$ ). $D_{A}$ is a dummy variable set equal to 1 if the subject adopted the price guarantee, $D_{P}$ is

$28 \Delta_{P / S}^{B S L}, \Delta_{P / S}^{P B 2 B}, \Delta_{P / S}^{P B 2 M}$ are positive and significant. However, $\Delta_{P / S}^{P B 1 B}$ is not significants and $\Delta_{P / S}^{P B 1 M}$ is negative and significant. 
a dummy variable set equal to one for prices (profits) of the sessions in which subjects are matched using a partners protocol, and $\mu_{i t}=\alpha_{i}+\varepsilon_{i t}$ where $\alpha_{i}$ are the individual effects that are considered as random effects and $\varepsilon_{\mathrm{it}}$ is the error term.

By construction, $\beta_{0}$ is the mean price (profit) for the non-adopters in a strangers protocol session, $\beta_{2}$ is the average variation to this price (profit) due to the change from a random to a partners protocol. Further, $\beta_{1}\left(\Delta_{S}^{A}\right)$ and $\beta_{1}+\beta_{3}\left(\Delta_{P}^{A}\right)$ are the average differential between the prices (profits) of the adopters and non-adopters in the stranger and partner sessions, respectively.

Insert Table 7 here

The panel estimates of (6) for posted prices and profits appear in Table 7. Let us start summarizing the results we obtain for posted prices. PMG adoption produces higher posted prices as $\Delta_{P M B-S}^{A}$ is positive and significant (estimated average increase for posted prices is 65.09). For PBGs we obtain different results for strangers and partner sessions. As for the strangers sessions, whereas adopters set higher posted prices than non-adopters in the soft-PBG sessions $\left(\Delta_{P B 1 B-S}^{A}=190.64\right.$ is significant at $1 \%$ level), prices set by adopters are not significantly different from those set by non adopters in the aggressive-PBG sessions $\left(\Delta_{P B 2 B-S}^{A}\right.$ is not significantly different from 0). Nevertheless, when subjects are matched using a partners protocol, adopters' prices are higher than non-adopters' ones both in the soft-PBG and the aggressive-PBG sessions (both $\Delta_{P B 1 B-P}^{A}=107.45$ and $\Delta_{P B 2 B-P}^{A}=110.36$ are significant at $1 \%$ level). 
Adopters' profits in the PMG sessions are higher than those of non-adopters, as $\Delta_{P M G-S}^{A}=3303$ is significant at $1 \%$ level. For the PBG sessions the existence of differences in profits between adopters and non-adopters depends only on the aggressiveness of the price beating promise. Independently of the matching rule, in the soft-PBG sessions there is no difference between the profits obtained by adopters and non-adopters $\left(\Delta_{P B 1 B-S}^{A}\right.$ and $\Delta_{P B 1 B-P}^{A}$ are not significantly different from 0$)$. However, in the aggressive-PBG sessions profits for adopters are lower than for nonadopters, as both $\Delta_{P B 2 B-S}^{A}$ and $\Delta_{P B 2 B-P}^{A}$ are negative and significant (these are -3995 and -22568 , respectively).

Hence the effects of PBG adoption on posted prices and profits can be summarized in the following way:

Result 5: When PMG is a business strategy, posted prices and profits of adopters are higher than those of non-adopters

Result 6: When PBG is a business strategy, posted prices of adopters are higher than those of non-adopters except in the aggressive-PBG stranger sessions.

Result 7: When PBG is a business strategy and independently of the matching mechanism, profits of non-adopters are not lower than profits of adopters. Specifically, with aggressive-PBG profits of non-adopters are higher than profits of adopters, and with

As for PBGs, both for the strangers and partners sessions rates of adoption with soft-PBG are larger than with aggressive-PBG (Figures 8 to 11). Result 9 can be used to explain these different patterns of adoption: whereas with soft-PBG adopters' profits are not significantly different of non-adopters' profits, with aggressive-PBG non-adopters' profits are higher than adopters' profits. 


\section{Insert Figures 7-11 here}

\section{Concluding Remarks}

In this paper we report results from experimental differentiated duopolies with price guarantees. Our findings can be seen as a bridge between the anticompetitive role of price matching reported in Fatas and Mañez (2007) and the procompetitive role of strong price beating reported in Fatas et al. (2005). Contrary to the dichotomous approach used in previous experimental work and most theoretical models, our treatments capture the fierceness of price undercutting guarantees, as they are run under three different values of a continuous parameter space ranging from price matching to aggressive price beating.

We show that the overall effect of a low price guarantee does not depend on the qualitative difference between price matching and price beating, as the theoretical analysis suggests, but rather on the aggressiveness of the undercutting promise. In that sense, the effects of moderate price beating on effective price levels are much more similar to those of price matching rather than to those of aggressive price beating. In fact, contrary to the pro-competitive role of aggressive price beating of the "double-the-difference" type, both price matching and moderate price beating have a clear anticompetitive effect.

Our results are obtained under a spectrum of experimental conditions implying different levels of difficulty for each one of the benchmark predictions to be reached. Thus, the robustness of the result on the pro-competitive character of aggressive price beating is confirmed in sessions run under a partner matching protocol. In an analogous way, the anti-competitive effects of price matching and soft price beating are also obtained in sessions run under a stranger matching protocol. However, it is important to note that these results concern effective prices obtained 
after the guarantees are applied on posted prices. An interesting finding related to this is that the adoption of price guarantees positively correlates with higher posted prices, which may imply a necessary distinction between anti-competitive intentions and anticompetitive results reflected on higher effective prices. That is, even if a given guarantee has a pro-competitive effect on final prices (after the guarantee is applied), high posted prices are still an evidence of firms' efforts to signal cooperative intentions.

The reported adoption levels are compatible with a rational behavior by our subjects in the corresponding decision stage, as they tend to adopt more the profitable ones (price matching and soft price beating) than they adopt the unprofitable ones (aggressive price beating).

In terms of policy implications, our findings call for a case-by-case treatment of low price guarantees. However, if the distinction between a moderate and an aggressive price beating guarantee is feasible, antitrust authorities should follow Edlin's (1997) recommendation of maintaining a cautious policy only in the case of price matching and moderate price beating, whereas they should adopt a more permissive attitude towards aggressive price beating guarantees. 


\section{References}

Arbatskaya, M., Hviid, M. and G. Shaffer (1999) Promises to match or beat the competition: evidence from retail tire prices, Advances in Applied Microeconomics 8, $123-138$.

Arbatskaya, M., Hviid M. and G. Shaffer (2004) On the incidence and variety of low price guarantees, Journal of Law and Economics, 47, 307-332.

Arbatskaya, M., Hviid, M. and G. Shaffer (2006) On the use of low-price guarantees to discourage price cutting, International Journal of Industrial Organization, 24, 1139-1156,

Baye, M.R. and D. Kovenock (1994) How to sell a pickup truck: "beat-orpay" advertisements as facilitating devices, International Journal of Industrial Organization, 12, 21-33.

Brandts, J. and D. Cooper (2006) A change would do you good. An experimental study on how to overcome coordination failure in organizations, American Economic Review, 96, 669-693.

Brandts, J., D. Cooper and E. Fatas (2007) Leadership and overcoming coordination failure with asymmetric costs, Experimental Economics, 10, 269-284.

Chen, Z. (1995) How low is a Guaranteed-lowest-price?, Canadian Journal of Economics, 28, 683-701.

Chen, J. and Q. Liu (2007a) Are low-price guarantees anti-competitive? An analysis through a natural experiment. Available at SSRN: http://ssrn.com/abstract $=989595$.

Chen, J. and Q. Liu (2007b) Price level, price dynamics, and low-price guarantees. mimeo.

Chen, Y., C. Narasimhan and Z.J. Zang (2001) Consumer heterogeneity and competitive price-matching guarantees, Marketing Science, 20, 300-314. 
Corts, K.S. (1995) On the robustness of the argument that price matching is anti-competitive, Economic Letters, 47, 417-421.

Corts, K.S. (1997) On the competitive effects of price matching policies, International Journal of Industrial Organization, 15, 283-299.

Datta, S. and J. Pate (2009) An experimental examination of competitor-based price matching guarantees, Journal of Economic Behavior and Organization 70, 342-360.

Deck, C. A. and B. Wilson (2003) Automated pricing rules in electronic posted offer markets, Economic Inquiry, 41, 208-223.

Dixit, A. and B. Nalebuff (1991) Thinking strategically, in W.W. Norten \& Company, Inc., New York, N.Y.

Doyle, C. (1988) Different selling strategies in Bertrand oligopoly, Economic Letters, 28, 387-390.

Dugar, S. (2005) Do price-matching guarantees facilitate collusion? An experimental study, University of Arizona Working paper, Department of Economics, available at: econ.arizona.edu/downloads/ working papers/Econ-WP05-02.pdf

Dugar, S. and T. Sorensen (2006) Hassle costs, price-matching guarantees and price competition: an experiment, Review of Industrial Organization, 28, 359-378.

Dugar, S. (2007) Price-matching guarantees and equilibrium selection in a homogenous product market: an experimental study, Review of Industrial Organization, 30, 107-119.

Edlin A. (1997) Do guaranteed-low price policies guarantee high prices, and can antitrust rise to the challenge?, Harvard Law Review, 111, 528-575.

Fatas, E. and J. Mañez (2007) Are low price compromises collusion guarantees?, Spanish Economic Review, 9, 59-77. 
Fatas, E.; N. Georgantzís, J. Mañez and G. Sabater-Grande (2005) Procompetitive price beating guarantees. Experimental Evidence, Review of Industrial Organization, 26, 115-136.

Urs Fischbacher (2007) z-Tree: Zurich toolbox for ready-made economic experiments, Experimental Economics, 10, 171-178.

Gwin and VanHoose (2010) Search costs, sticky prices and markups, Applied Economics, forthcoming.

Hess, J and E. Gerstner (1991) Price matching policies: an empirical case, Managerial and Decision Economics, 12, 305-315.

Huang, Chih-Jen, Chao, Ching-Hsiang and Liao, Tsai-Ling (2010) The joint decision to signal through IPO underpricing and lockup, Applied Economics Letters, 17, 955-961.

Hviid, M. and G. Shaffer (1994) Do low price guarantees facilitate tacit collusion?, University of Michigan working paper, 94-02.

Hviid, M. and G. Shaffer (1999) Hassle costs: the Achilles' heel of pricematching guarantees, Journal of Economics and Management Strategy, 8, 489-521.

Jain, S. and J. Srivastava (2000) An experimental and theoretical analysis of price-matching refund policies, Journal of Marketing Research, 37, 351-362.

Kaplan, T. (2000) Effective price-matching: a comment, International Journal of Industrial Organization, 18, 1291-1294.

Lai, G., Debo, L.G. and Sycara, K. (2008) Buy Now and Match Later: The Impact of Posterior Price Matching on Profit with Strategic Consumers, Available at SSRN: http://ssrn.com/abstract=1094562.

Lin, Y.J. (1988) Price matching in a model of equilibrium price dispersion, Southern Economic Journal, 55, 57-69. 
Lindberg, L. (2008) Low price guarantee, are you guaranteed the lowest price, Available at ESSAYS http://www.essays.se/essay/ec18e53e9b/.

Logan, J. W. and R. W. Lutter (1989) Guaranteed Lowest Prices: Do they Facilitate Collusion, Economics Letters, 31, 189-192.

Lurie, N.H. and J. Srivastava (2005) Price-matching guarantees and consumer evaluations of price information, Journal of Consumer Psychology, 15, 149-158.

Mañez, J.A. (2006) Unbeatable value: low price guarantee or advertising strategy, Journal of Economics and Management Strategy, 15, 143-166.

Milyo, J. and J. Waldfogel (1999) The effects of price advertising on prices: evidence on the wake of 44 Liquormart, American Economic Review, 89, 1081-1096.

Moorthy, S. and R. Winter (2006) Price-matching guarantees, Rand Journal of Economics, 37, 449-465.

Park, B.U. and J.S. Marron (1990) Comparison of data-driven bandwidth selectors, Journal of the American Statistical Association, 85, 66-72.

Salop, S. (1986) Practices that (credibly) facilitate oligopoly coordination, in J. Stiglitz and F. Mathewson (eds), New Developments in the Analysis of Market Structure, MIT Press, Cambridge, MA.

Sargent, M. (1993) Economics upside-down: low price guarantees as mechanism for facilitating tacit collusion, University of Pennsilvania Law Review, 141, 2055-2118.

Sheater, S.J. and M.C. Jones (1991) A reliable data-based bandwidth selection method for kernel density estimation, Journal of the Royal Statistical Society, 53, 683-690.

Smith, M. D., J. Bailey and E. Brynjolfsson (1999) Understanding digital markets, in Brynjolfsson and Kahin, eds., Understanding the digital economy, MIT Press. Stigler, G. (1964) A Theory of oligoply, Journal of Political Economy, 72, 44-61. 
Srivastava, J. (2001) A Consumer perspective on price matching refund policies: effect on price perceptions and search behavior, Journal of Consumer Research, 28, 296-308.

Srivastava, J. and N. Lurie (2004) Price matching refund policies as signals of store price image?, Journal of Retailing, 80, 117-128.

Van Huyck, J., R. Battalio and R. Beil (1990) Tacit Coordination Games, Strategic Uncertainty, and Coordination Failure, American Economic Review, 80, 234248. 


\section{APPENDIX I: INSTRUCTIONS (TRANSLATED FROM SPANISH)}

The aim of this experiment is studying decision-making in economic environments. The rules are pretty simple. You will be privately paid in cash at the end of the experiment according to your accumulated earnings. Feel free to any questions regarding these instructions. Any communication among the participants is strictly forbidden. Below is some useful information:

1. This experiment lasts 50 Rounds. (For treatments with stranger RMM) In each round, you will be randomly matched with another subject to create pairs of subjects. You will never know the identity of your partner. (For treatments with partner RMM) In the first round, you will be randomly matched with another subject to create pairs of subjects, kept constant throughout the session. You will never know the identity of your partner.

2. In the experiment you are a firm and, in each round, you have to decide about the selling price of the only product you produce. The available price range is between 30 and 1,000 ExCUs (an Experimental Currency Unit).

3. (For all but baseline treatments) We will call this price the posted price.

4. (Only in treatments with price beating as a business strategy) You also have to decide whether you will offer a price beating guarantee. If you do so and your posted price exceeds the posted price of the other firm, your effective selling price will be your price minus twice the difference between your price and the other firm's posted price. Then, your effective selling price will be calculated in the following way: $p_{1}^{e}=p_{1}^{p}-2\left(p_{1}^{p}-p_{2}^{p}\right)$ 
5. (Only in treatments with price matching as a business strategy) You also have to decide whether you will offer a price matching guarantee. If you do this and the other firm posts a price lower than yours then your effective price will be the latter. That is, if your posted price exceeds the posted price of the other firm, your effective selling price will be the other firm's posted price.

6. (Only for soft/aggressive price beating market institution treatments) Your posted price may differ from the effective selling price as there is a pricing rule in the market called price beating guarantee. This rule compares posted prices in the market and allows consumers to buy the product at the lower firm's price, so that if your posted price exceeds the posted price of the other firm, your effective selling price will be your price minus $10 \%$ of/twice the difference between your price and the other firm's posted price.

7. (Only in treatments with price matching as a market rule) Your posted price may differ from the effective selling price as there is a pricing rule in the market called price matching guarantee. This rule compares posted prices in the market and allows consumers to buy the product at the firm offering the lowest price, so that if your posted price exceeds the posted price of the other firm, your effective selling price will be the other firm's posted price.

8. (Only for business strategy treatments) There are two types kinds of rounds in this experiment:

a. $\quad$ Round $1,6,11, \ldots, 46)$, in which you have to make a decision about both your posted price and whether you offer a price beating guarantee. 
b. All other rounds, in which you have to decide on your posted price.

9. For each round, the time structure of the experiment is the following. Every time you make a decision, you will receive information concerning:

a. (Only for baseline treatments) Your price, demand and profits and the price, demand and profits of the firm with which you compete in each round.

b. (Only for market rule treatments) Your posted price, effective selling price, demand and profits and the posted, effective price, demand and profits of the firm with which you compete in each round.

c. (Only for business strategy treatments) Your posted price, effective selling price, demand and profits and the posted, effective price, demand and profits of the firm with which you compete in each round. You will also receive information concerning the price guarantees of both firms.

8 Demand in each round depends only on your firm's decision and the decision of the other firm in the market. Once these two decisions have been made, you will know your product's demand and your firm's profits in the round.

9 At the end of the experiment, you will receive a monetary reward equal to your firm's profits exchanged at a rate of 3,000 ExCUs for 1 Spanish peseta (or 500,000 ExCUs $=1 €$ ). 


\section{APPENDIX II -ADDITIONAL QUANTITATIVE ANALYSIS}

\section{A) DENSITY FUNCTIONS}

Aggregating the individual observations obtained in the last 25 rounds, we can estimate the density functions presented in figures A-1 to A-5. On them, we see that the two benchmark solutions (non cooperative and collusive) constitute systematic attractors of business strategies. The steepest accumulation of observations around a benchmark solution is observed in the case of price matching guarantees in which prices agglomerate around the collusive prediction. On the contrary, figures A-1 to A5 indicate that price beating guarantees produce the highest dispersion of observations under all treatments in which they are implemented. In all other cases, intermediate levels of dispersion are observed, mostly around the non cooperative prediction. This result should also be taken into account when stating the conclusions in terms of economic policy, as it affects the confidence with which our findings should be seen as a basis for market regulation.

\section{B) COMPARISON OF PROFITS ACROSS TREATMENTS}

Table A-1 shows actual profits as a percentage of Bertrand and CS profits (for rounds 1 to 25 and rounds 26 to 50). Profits get closer to the Bertrand equilibrium prediction as we move from the initial 25 rounds to the last 25 ones. As we would have expected, treatment PMG-SB reach the highest profits among all towards the second half of the session.

Table A-2 estimates the profits differentials across treatments, using the same estimation technique explained in the main text for Table 3, as described in equation (5) and section 3. In Table A-3 we show the $\chi^{2}(1)$ tests comparing each one of the estimated average prices (profits) both to the BNE and CS price profit. 
Whilst the average profit for the BSL session in which subjects are matched using a partners protocol is not significantly different from the BNE profit, average profit in the corresponding stranger sessions is below this profit (average profit for the strangers protocol sessions is 112308 and for the partners protocol session 116439). Moreover, the fact that $\Delta^{B S L-P / B S L-S}$ is not significant indicates that different matching protocols do not imply significantly different profits in the BSL sessions. ${ }^{29}$

The introduction of PMG in the stranger sessions either as a market rule or as a business strategy results in significant profits increases. As a result, neither the average profit in the PMG-B (120175) nor the one in the PMG-M (122198) sessions is significantly different to the CS profit (see Table 5).Further, the average profit increase observed when PMG is introduced as a market rule is not significantly different than the one observed when PMG is introduced as a business strategy $\left(\Delta_{S}^{P M G-M / P M G-B}=\beta_{2}-\beta_{1}=2022.90\right.$ with $\mathrm{p}$-value 0.392).

Both in stranger and partner sessions, the introduction of either an aggressive or a soft-PBG and either as a market rule or as a business strategy results in lower average profits. In fact, average profits for the sessions in which any of the two kinds of PBG is available are always below the BNE profit. Additionally, whereas with softPBG average profit is similar both in the business strategy and the market rule sessions, in the aggressive-PBG sessions average profit is significantly lower when PBG is a market rule.

When a strangers protocol is used, average profit with soft-PBG as a market rule and as a business strategy are $8077\left(-\Delta_{S}^{P B 1 G-M / B S L}\right)$ and $6250\left(-\Delta_{S}^{P B 1 G-B / B S L}\right)$ lower than the average profit in the strangers session without PGs, respectively. In the same line, average profit with aggressive-PBG as a market rule and as a business strategy

\footnotetext{
${ }^{29}$ This result is due to the fact that BSL-P average profit (116439) is in an intermediate situation with
} respect to the lower BSL-S average profit (112308) and the higher BNE profit (117600). 
are respectively $12811\left(-\Delta_{S}^{P B 2 G-M / B S L}\right)$ and $5492\left(-\Delta_{S}^{P B 2 G-B / B S L}\right)$ lower than average profit in the strangers session in which no PGs are available.

As for the partner sessions, average profits with soft-PBG as a market rule and as business strategy are respectively $11408\left(-\Delta_{P}^{P B 1 G-M / B S L}\right)$ and 10609 $\left(-\Delta_{P}^{P B 1 G-B / B S L}\right)$ lower than the average profit in the partner session with no PGs. Analogously, average profit with aggressive-PBG as a market rule and as a business strategy are respectively $27685\left(-\Delta_{P}^{P B 2 G-M / B S L}\right)$ and $16516\left(-\Delta_{P}^{P G 2 B-B / B S L}\right)$ lower than the average profit in the partner session without PGs .

In what follows, we analyse the effects on average profits of different price guarantees for each of the two protocols. In the strangers protocol sessions, if the guarantee is a business strategy, average effective profit with PMG is significantly higher than those corresponding to soft-PGB and aggressive-PBG $\left(\Delta_{S}^{P M G-B / P B 1 G-B}=14387\right.$ and $\Delta_{S}^{P M G-B / P B 2 G-B}=13359$ with $p$-value 0.000$)$. Further, softPBG and aggressive-PBG average profits are not significantly different $\left(\Delta_{S}^{P B 1 G-B / P B 2 G-B}=-1028\right.$ with $p$-value $\left.=0.659\right)$. However, for the stranger sessions in which the price guarantee is a market rule, the PMG average profit is higher than the soft-PBG average profit $\left(\Delta_{S}^{P M G-M / P B 1 G-M}=17697\right.$ with $p$-value 0.000$)$ and this is higher than the aggressive-PBG one $\left(\Delta_{S}^{P B 1 G-M / P B 2 G-M}=7433\right.$ with $p$-value 0.042).

As for the partner sessions, regardless of whether the price guarantee is introduced as a market rule or a business strategy soft-PBG induces higher profits than aggressive-PBG $\left(\Delta_{P}^{P B 1 G-B / P B 2 G-B}=5546\right.$ and $\Delta_{P}^{P B 1 G-M / P B 2 G-M}=16277$ with $p$ values 0.093 and 0.000 , respectively).

The results on profits can be summarized as follows: 
Result A1: If no PGs are included among the alternatives, the average profit of the stranger sessions is below the Bertrand-Nash equilibrium profit, and the average profit of the partner session is not significantly different from it.

Result A2: The introduction of PMG either as a business strategy or a as a market rule increases significantly average profits. As a result, with PMG average profits are at the level of the CS profit.

Result A3: When PBG is included among the alternatives, independently of the matching mechanism, the aggressiveness of the price beating and whether the PBG is a market rule or a business strategy, average profits are lower than when no guarantee is available to subjects.

Result A4: The effects of the price guarantees on profit depend both on whether the price guarantee is a price matching or a price beating one and on the aggressiveness of the price beating promise.

Result A4-a: If the matching protocol is strangers and the PGs are introduced as business strategies, average profit under PMG is higher than those under both soft and aggressive PBG. Further, profit under the soft-PBG is not significantly different to that under the aggressivePBG.

Result A4-b: If the matching protocol is strangers and the PGs are introduced as market rules, average profit under the PMG is higher than those under PBGs. Further, average profit under the soft-PBG is higher than under the aggressive-PBG.

Result A4-c: If the matching protocol is strangers and regardless of whether the PBG is a market rule or business strategy, average profit under the soft-PBG is higher than that under the aggressive-PBG. 


\section{Acknowledgements}

This research was funded by the Spanish Ministry of Education (ECO 200804636/ECON), Bancaixa (P1 1B2007/14; P1 1A2007-06) and the Junta de Andalucia (P07-SEJ-03155). Part of this research was carried out when the second author was visiting the University of Cyprus and the LEM (University Paris II) whose hospitality is gratefully acknowledged. The authors thank Dan Kovenock, Jordi Brandts, Tibor Neugebauer, Antonio Fatás, Bruno Broseta, Henrik Orzen, Silviano Esteve and seminar attendants at Naples, Barcelona, Valencia, Reus, Strasbourg, Torino, Helsinki, Pamplona and Malaga for helpful comments. 
1

2

3

4

5

6

7

8

9

10

11

12

13

\section{FIGURES}

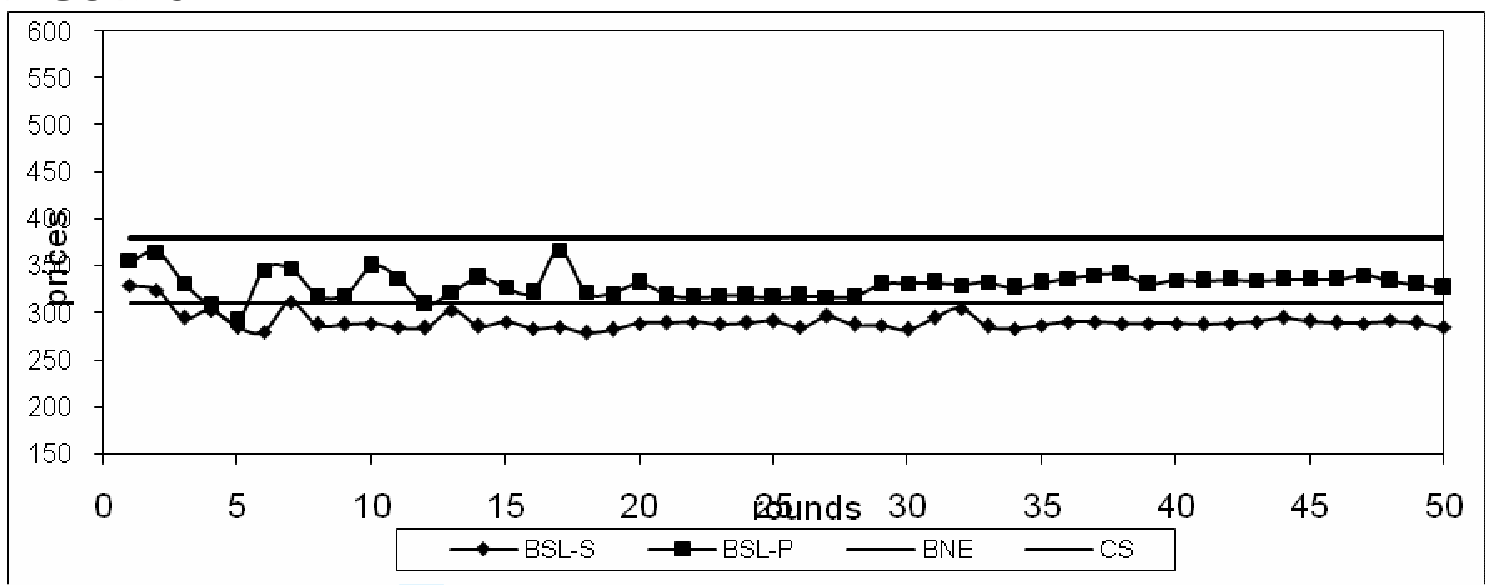

Figure 1: Evolution of average per round effective prices, BSL-S and BSL-P.

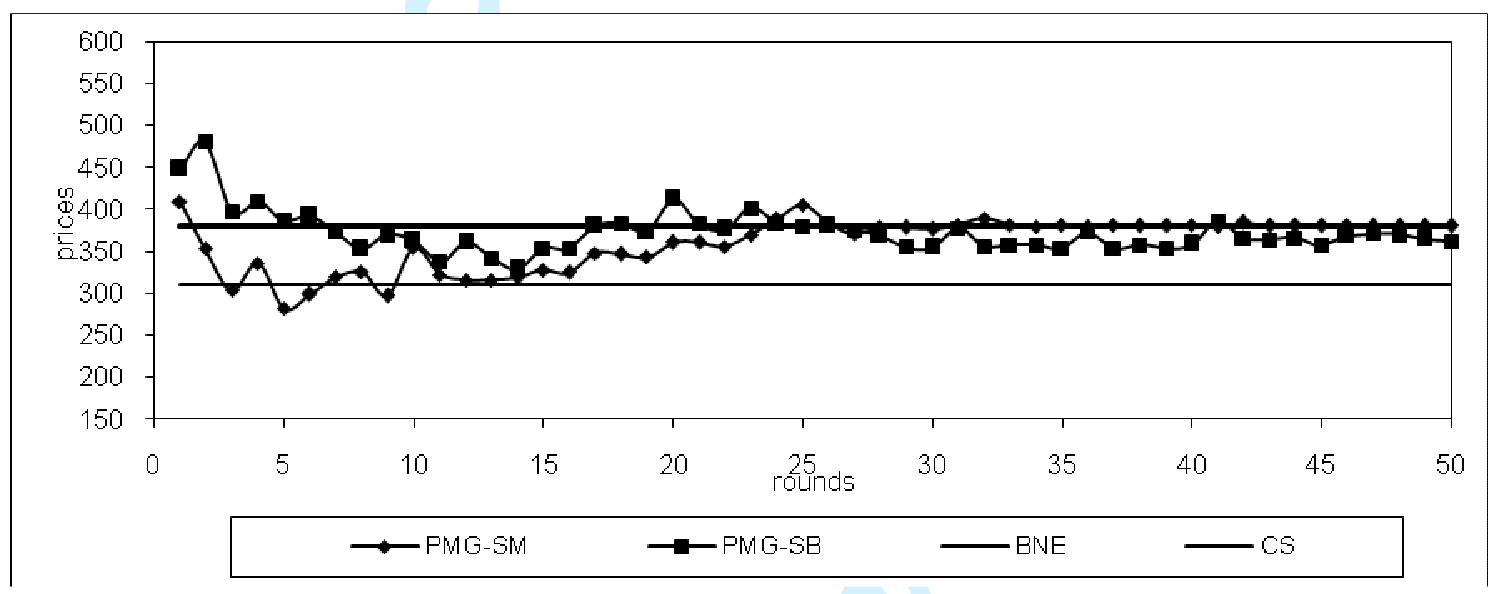

Figure 2: Evolution of average per round effective prices, PMM-S and PMB-S.

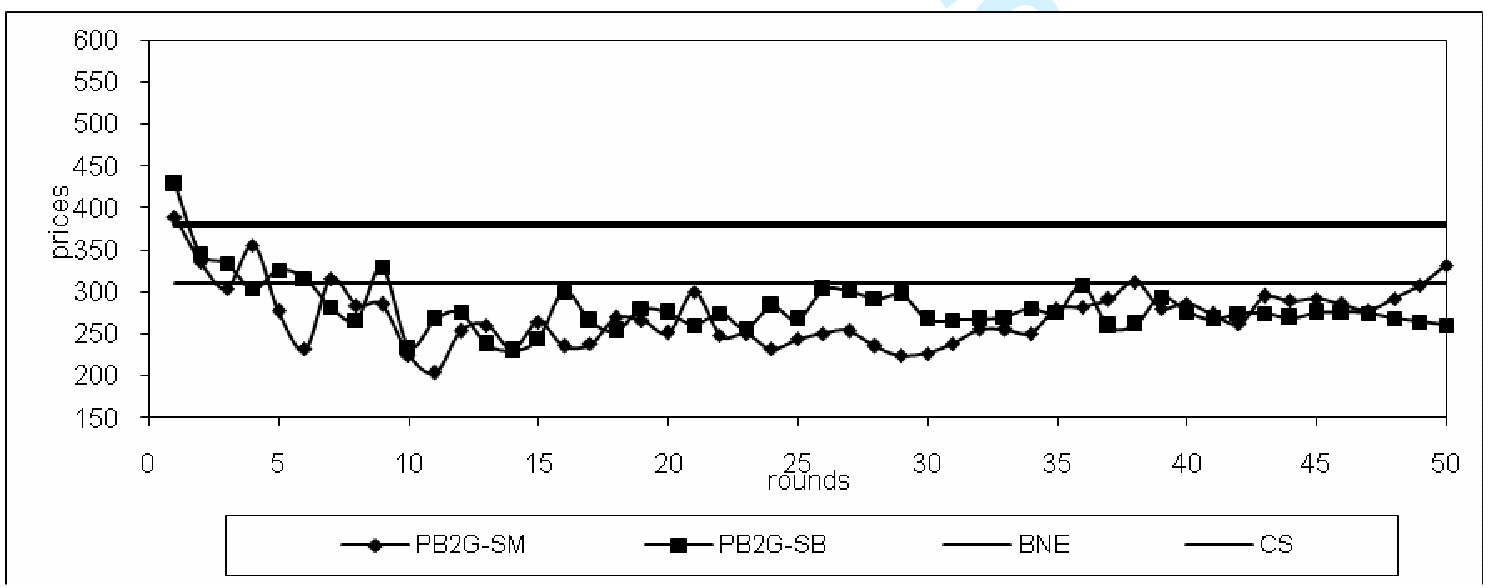

Figure 3: Evolution of average per round effective prices, PB2G-SM and PM2G-SB. 


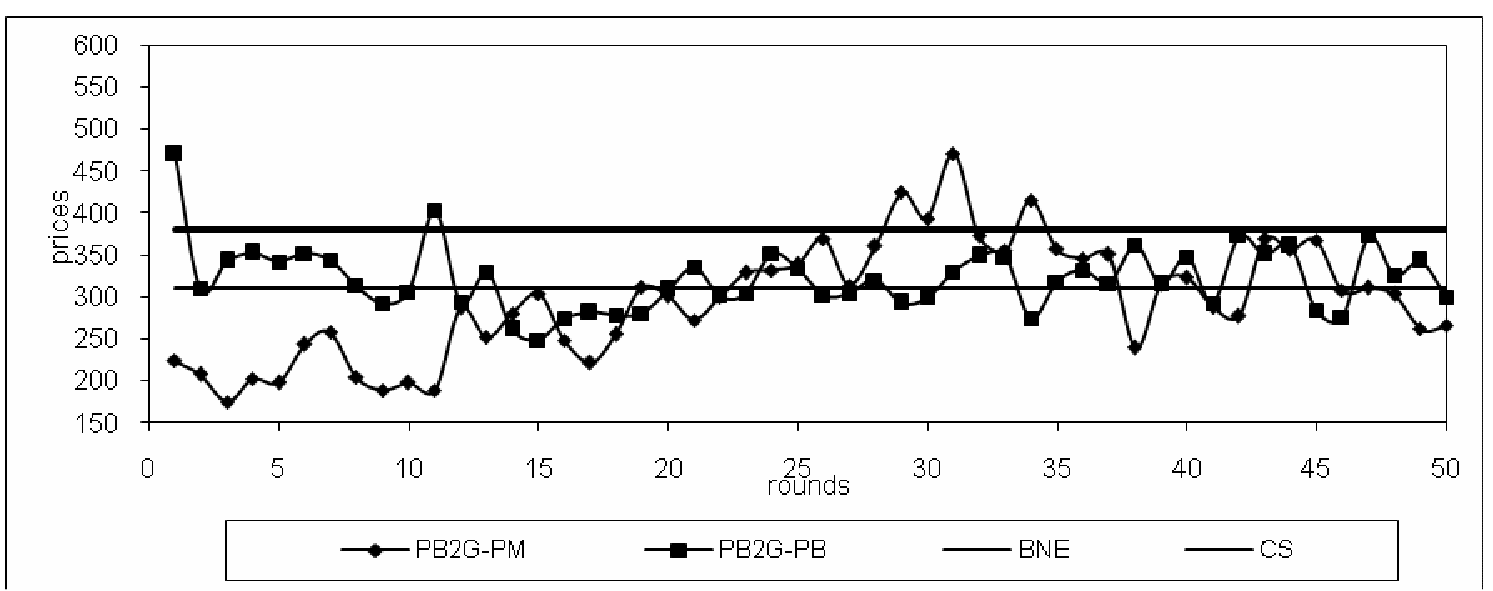

Figure 4: Evolution of average per round effective prices, PB2G-PM and PM2G-PB.

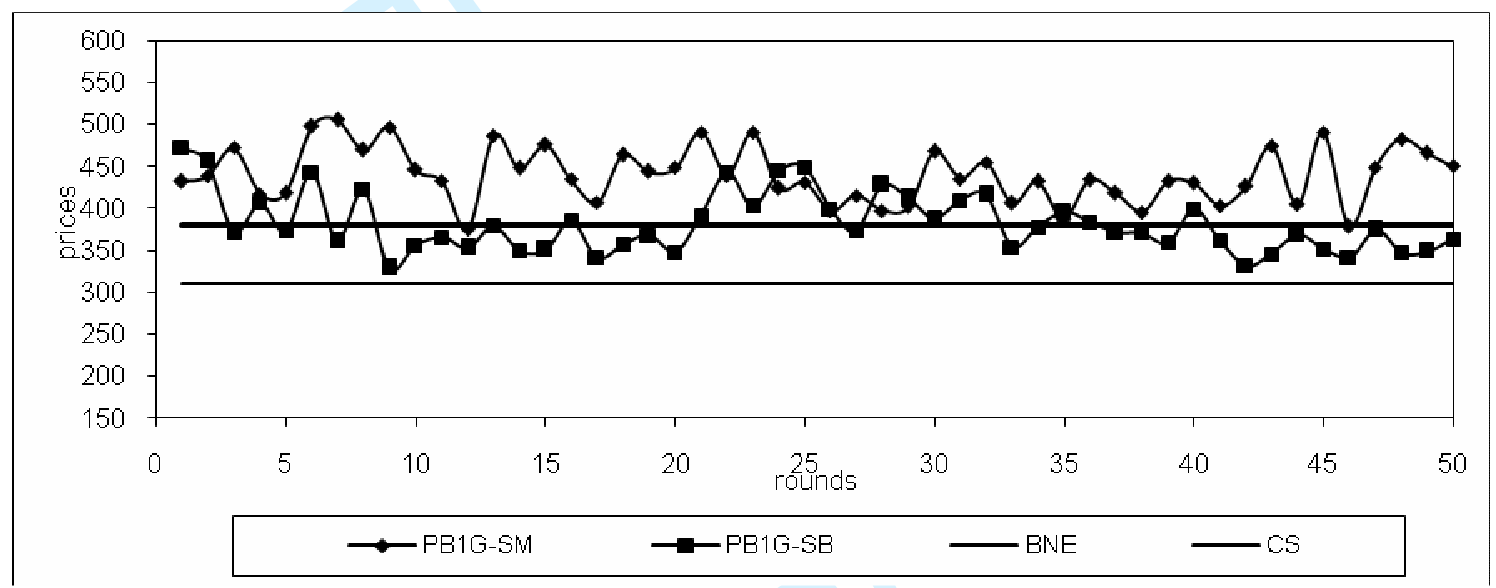

Figure 5: Evolution of average per round effective prices, PB1G-SM and PM1G-SB.

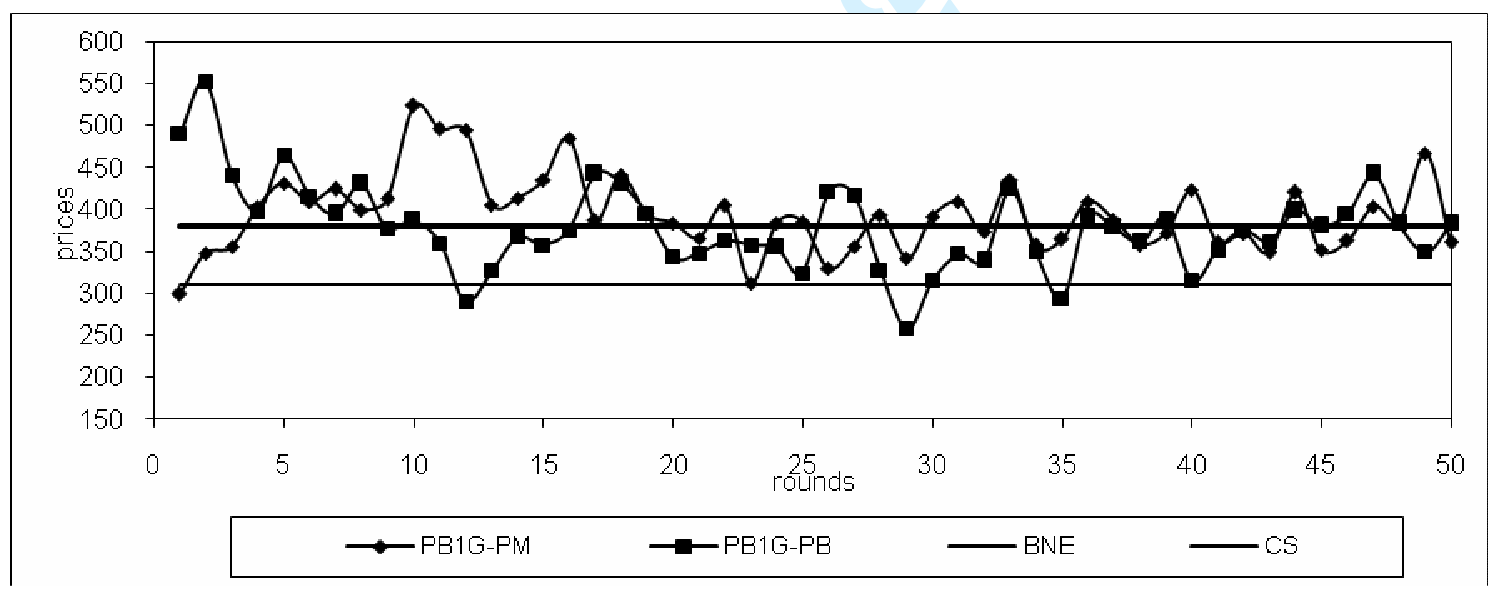

Figure 6: Evolution of average per round effective prices, PB1G-PM and PM1G-PB. 


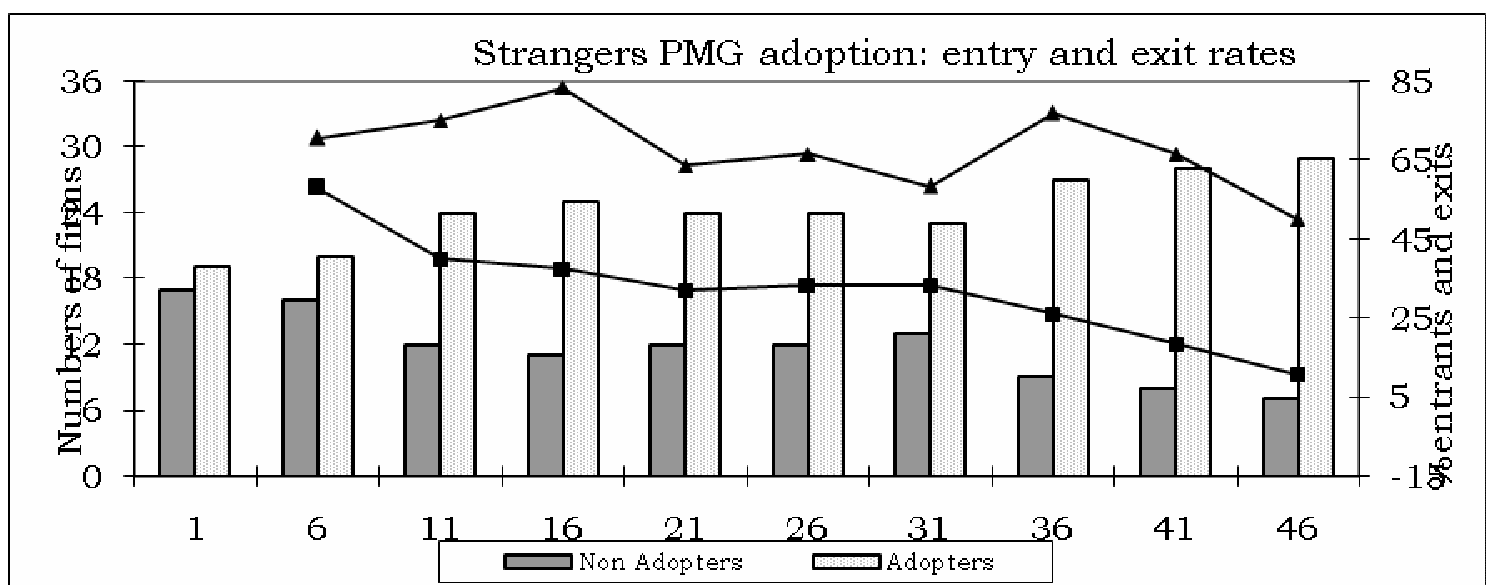

Figure 7: PMG-S adoption patterns

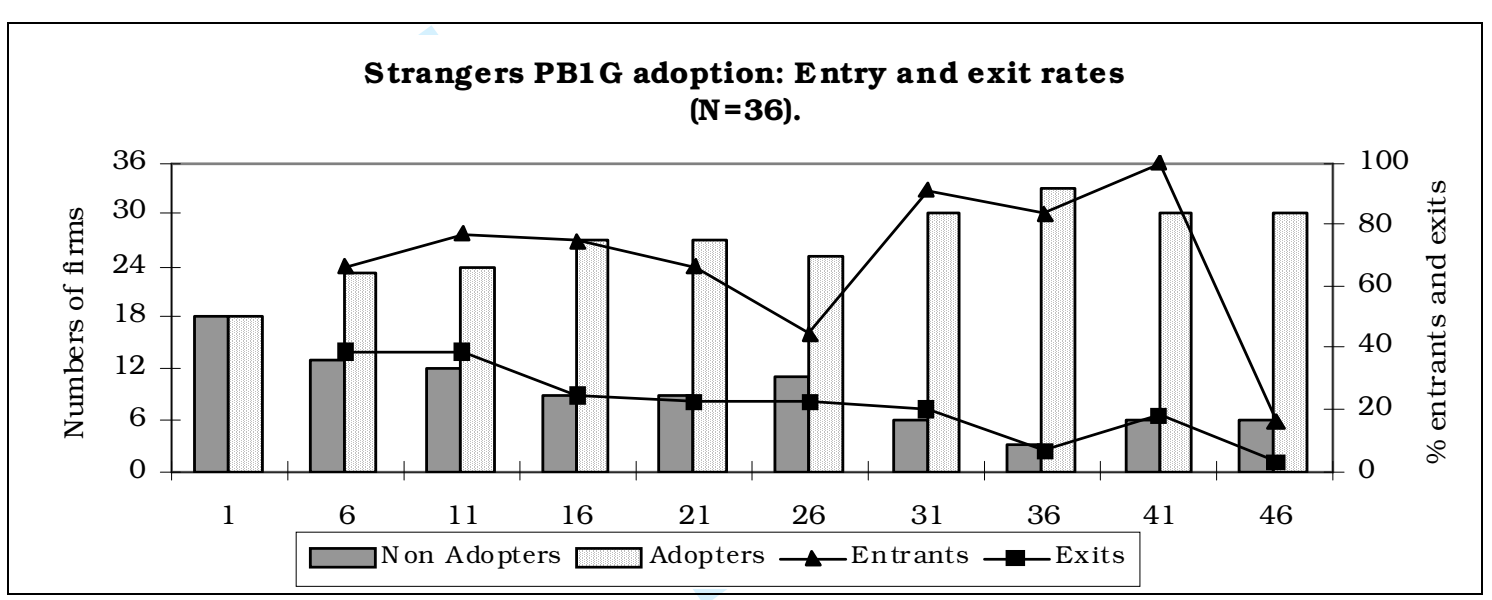

Figure 8: PB1G-S adoption patterns

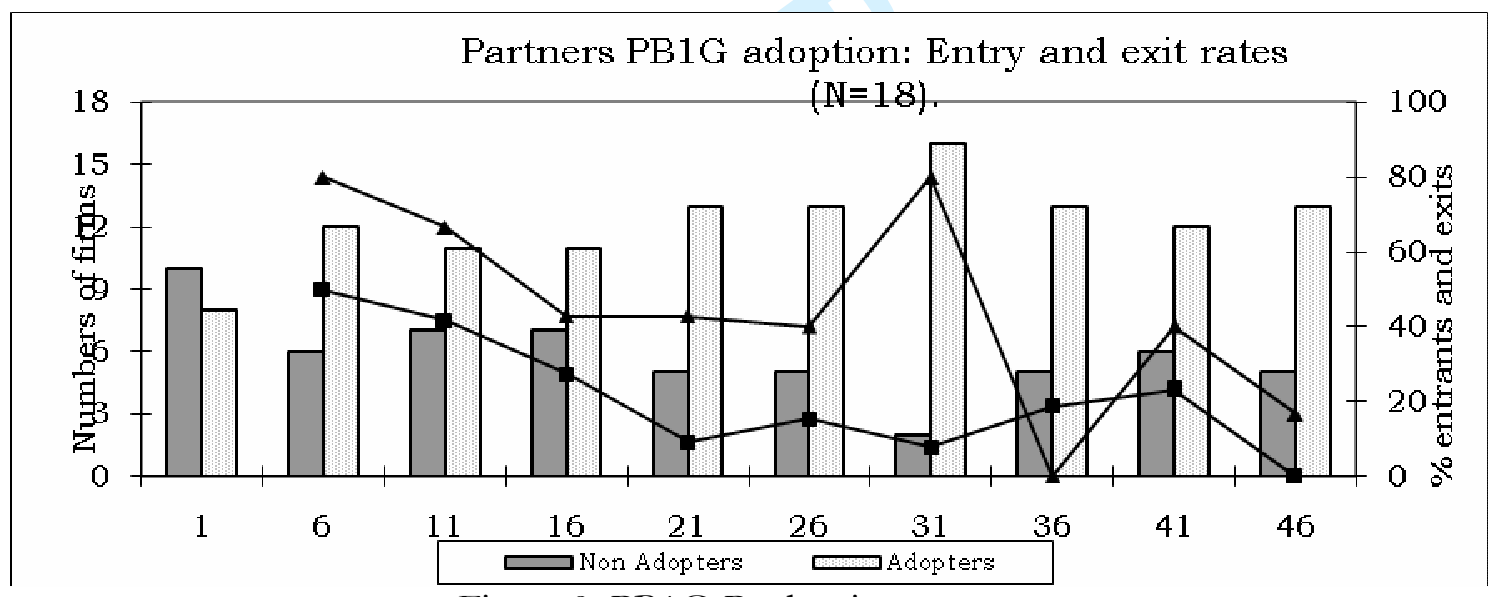

Figure 9: PB1G-P adoption patterns 


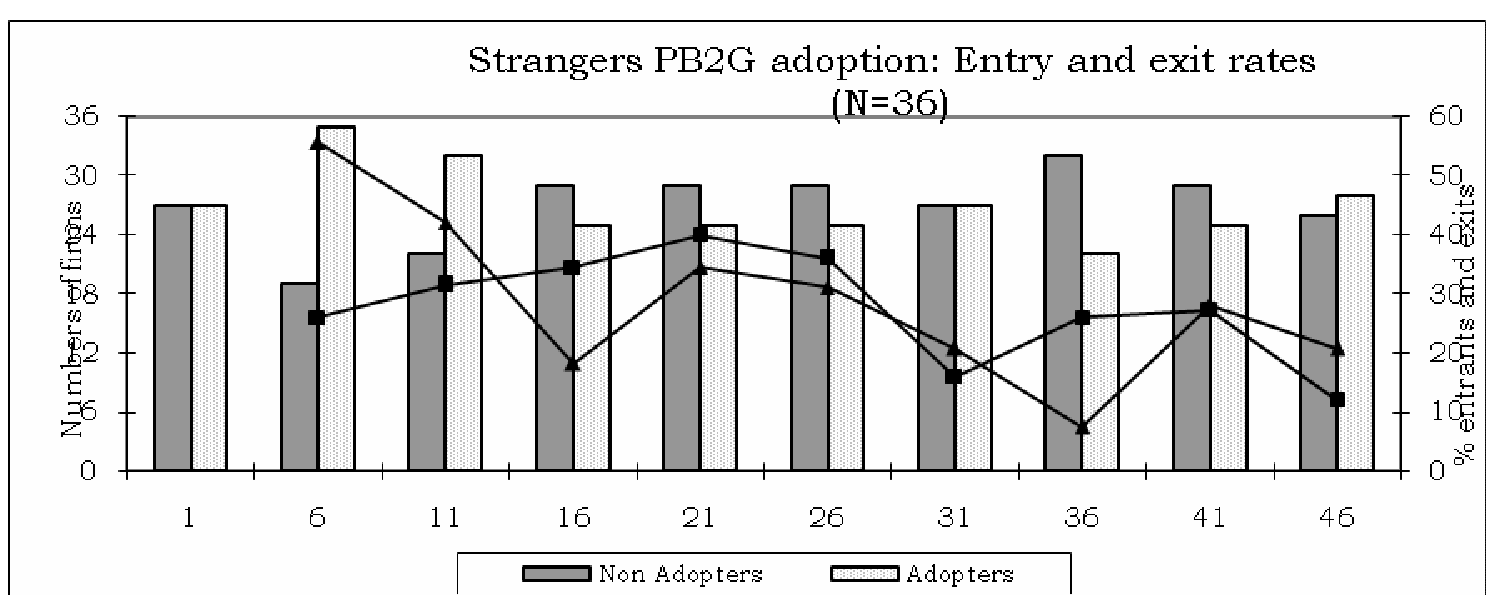

Figure 10: PB2G-S adoption patterns

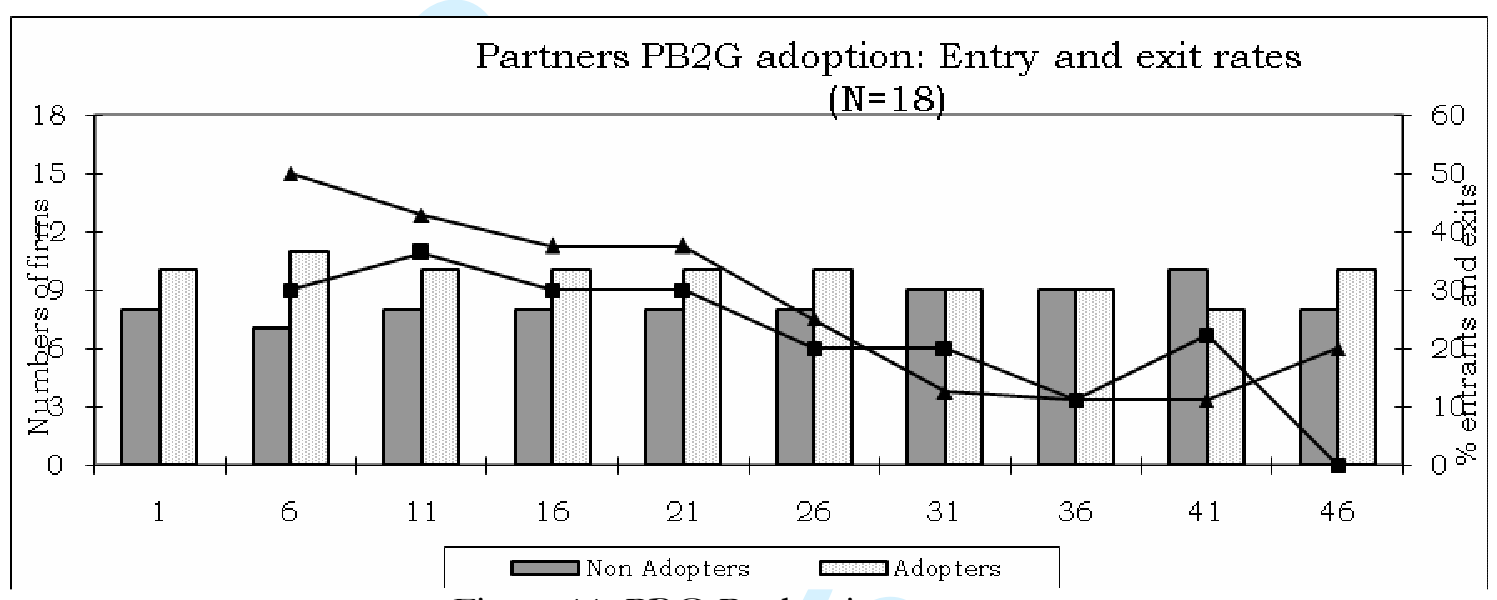

Figure 11: PBG-P adoption patterns 


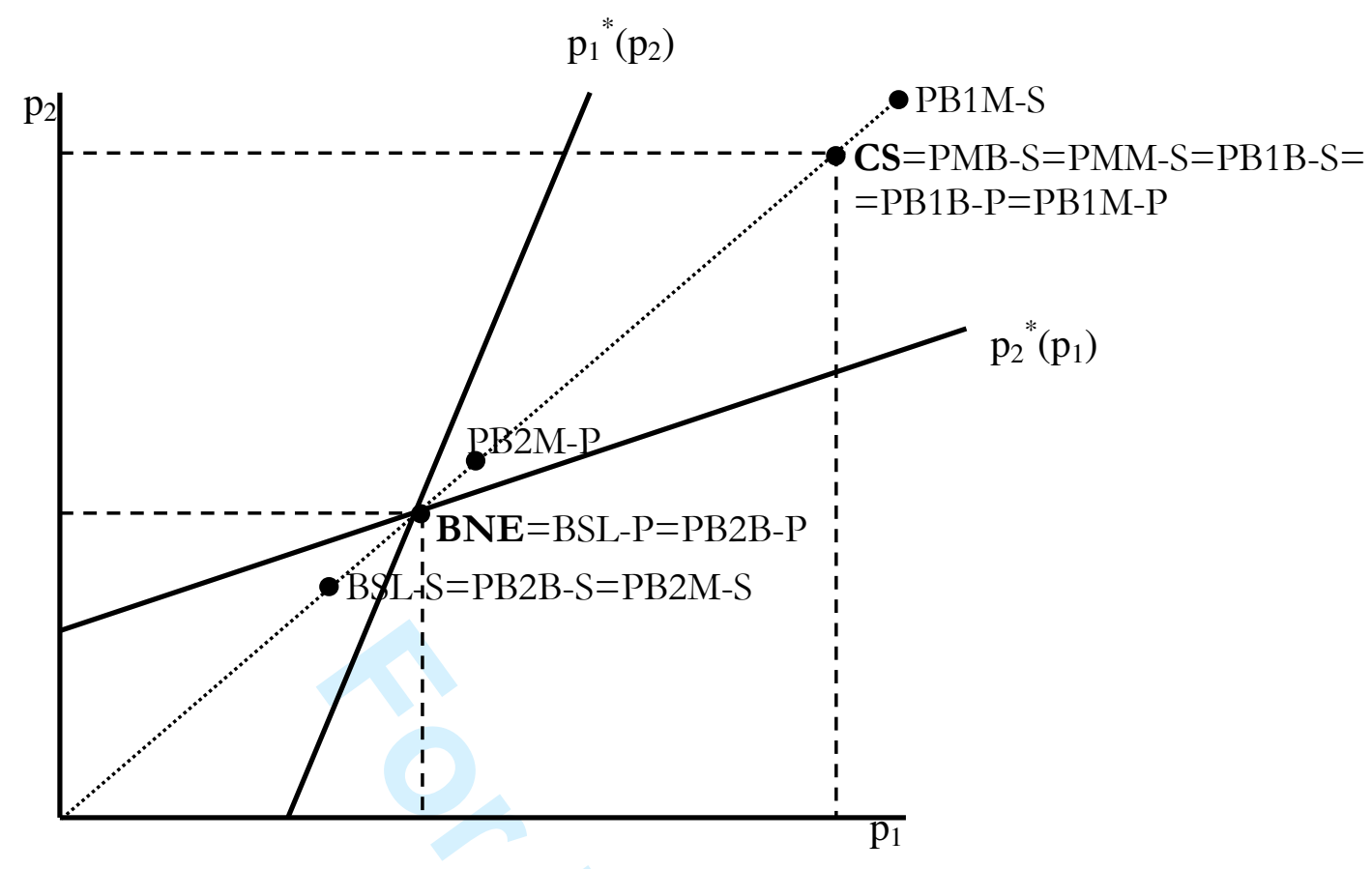

Figure 12: Summary of average effective prices 
TABLES

Table 1: Summary of testable hypotheses

\begin{tabular}{|c|c|c|c|}
\hline & $\alpha$ & PG adoption & Equilibrium prices \\
\hline $\begin{array}{l}\text { No Price } \\
\text { Guarantee }\end{array}$ & $\alpha=0$ & Not allowed & BS price \\
\hline $\begin{array}{l}\text { Exogenously } \\
\text { imposed PMG }\end{array}$ & $\alpha=1$ & $\begin{array}{l}\text { All firms adopt PMG } \\
\text { (exogenously imposed) }\end{array}$ & $\begin{array}{l}\text { Continuum of NE: any symmetric price } \\
\text { between the BS and the CS is an } \\
\text { equilibrium }\end{array}$ \\
\hline $\begin{array}{l}\text { Business strategy } \\
\text { PMG }\end{array}$ & $\alpha>1$ & $\begin{array}{l}\text { 1. No firm adopts PMG } \\
\text { 2. All firms adopt PMG }\end{array}$ & $\begin{array}{l}\text { 1. Both firms set the BS price } \\
\text { 2. Continuum of NE: any symmetric price } \\
\text { between the BS and the CS is an equilibrium } \\
\text { 3. Both firms set the BS price }\end{array}$ \\
\hline $\begin{array}{l}\text { Exogeneoulsy } \\
\text { imposed PBG }\end{array}$ & $\alpha>1$ & $\begin{array}{l}\text { All firms adopt PBG } \\
\text { (exogenously imposed) }\end{array}$ & Both firms set the BS price \\
\hline $\begin{array}{l}\text { Business Strategy } \\
\text { PBG }\end{array}$ & $\alpha>1$ & No firm adopts PBG & Both firms set the BS price \\
\hline
\end{tabular}


Table 2: Experimental Treatments Summary Table

\begin{tabular}{lllllll}
\hline \hline Treatments & $\alpha$ & $\begin{array}{l}\text { Matching } \\
\text { mechanism }\end{array}$ & Implementation Rule & $\begin{array}{l}\text { Sessions } \\
\text { Label }\end{array}$ & Markets & Subjects \\
\hline BSL-S & 0 & Strangers & -- & S11, S12 & 18 & 36 \\
BSL-P & 0 & Partners & -- & S13 & 9 & 18 \\
PMM-S & 1 & Strangers & Market rule & S21, S22 & 18 & 36 \\
PMB-S & 1 & Strangers & Business strategy & S31, S32 & 18 & 36 \\
PB2M-S & 2 & Strangers & Market rule & S41, S42 & 18 & 36 \\
PB2M-P & 2 & Partners & Market rule & S43 & 9 & 18 \\
PB2B-S & 2 & Strangers & Business strategy & S51, S52 & 18 & 36 \\
PB2B-P & 2 & Partners & Business strategy & S53 & 9 & 18 \\
PB1M-S & 1.1 & Strangers & Market rule & S61, S62 & 18 & 36 \\
PB1M-P & 1.1 & Partners & Market rule & S63 & 9 & 18 \\
PB1B-S & 1.1 & Strangers & Business strategy & S71, S72 & 18 & 36 \\
\hline \hline & 1.1 & Partners & Business strategy & S73 & 9 & 18 \\
\hline & & & & ToTAL & 171 & 342 \\
\hline
\end{tabular}


Table 3: Theoretical values of prices, demand and profits

\begin{tabular}{lrr}
\hline \hline & $\begin{array}{r}\text { Bertrand-Nash } \\
\text { Equilibrium (BNE) }\end{array}$ & $\begin{array}{r}\text { Collusive Solution } \\
(\mathrm{CS})\end{array}$ \\
\hline$p_{i}$ & 310 & 380 \\
$q_{i}$ & 420 & 350 \\
$\Pi$ & 117600 & 122500 \\
\hline \hline
\end{tabular}


Table 4: Observed price averages $(\mathrm{Av})$ and standard deviations (SD) (rounds 1 to 25 and rounds 26 to 50 )

\begin{tabular}{|c|c|c|c|c|c|}
\hline $\begin{array}{l}\text { Treatments } \\
\text { BSL-S }\end{array}$ & & $\mathrm{Av}_{1-25}$ & $\mathrm{SD}_{1-25}$ & $\mathrm{Av}_{26-50}$ & $\mathrm{SD}_{26-50}$ \\
\hline S-11 & $p_{i}$ & 280.70 & 67.29 & 284.74 & 44.97 \\
\hline S-12 & $p_{i}$ & 303.18 & 70.25 & 293.52 & 32.56 \\
\hline \multicolumn{6}{|l|}{ BSL-P } \\
\hline S-13 & $p_{i}$ & 328.19 & 117.24 & 331.32 & 59.25 \\
\hline \multicolumn{6}{|l|}{ PMM-S } \\
\hline \multirow[t]{2}{*}{ S-21 } & $p_{i}^{p}$ & 399.04 & 167.69 & 421.01 & 114.89 \\
\hline & $p_{i}^{e}$ & 316.84 & 120.29 & 380.60 & 21.42 \\
\hline \multirow[t]{2}{*}{ S-22 } & $p_{i}^{p}$ & 438.68 & 167.42 & 401.12 & 89.31 \\
\hline & $p_{i}^{e}$ & 363.66 & 122.08 & 379.33 & 11.18 \\
\hline
\end{tabular}

PMB-S

\begin{tabular}{llllll}
\hline S-31 & $p_{i}^{p}$ & 456.71 & 182.52 & 412.07 & 96.57 \\
& $p_{i}^{e}$ & 382.07 & 140.76 & 373.83 & 41.72 \\
S-32 & $p_{i}^{p}$ & 420.70 & 130.58 & 384.19 & 89.91 \\
& $p_{i}^{e}$ & 378.83 & 85.66 & 353.96 & 43.31
\end{tabular}

PB2M-S

\begin{tabular}{|c|c|c|c|c|c|}
\hline \multirow[t]{2}{*}{ S-41 } & $p_{i}^{p}$ & 386.72 & 143.31 & 324.50 & 61.23 \\
\hline & $p_{i}^{e}$ & 265.38 & 125.72 & 260.54 & 72.74 \\
\hline \multirow[t]{2}{*}{ S-42 } & $p_{i}^{p}$ & 433.60 & 165.64 & 380.69 & 96.07 \\
\hline & $p_{i}^{e}$ & 273.94 & 159.74 & 285.02 & 111.15 \\
\hline \multicolumn{6}{|l|}{ PB2M-P } \\
\hline \multirow[t]{2}{*}{ S-43 } & $p_{i}^{p}$ & 341.81 & 193.10 & 426.29 & 164.37 \\
\hline & $p_{i}^{e}$ & 252.36 & 179.82 & 340.18 & 171.62 \\
\hline \multicolumn{6}{|l|}{ PB2B-S } \\
\hline \multirow[t]{2}{*}{ S-51 } & $p_{i}^{p}$ & 328.56 & 102.88 & 295.51 & 45.78 \\
\hline & $p_{i}^{e}$ & 278.81 & 104.22 & 283.03 & 52.53 \\
\hline \multirow[t]{2}{*}{ S-52 } & $p_{i}^{p}$ & 399.82 & 185.37 & 308.57 & 67.51 \\
\hline & $p_{i}^{e}$ & 291.22 & 170.53 & 269.75 & 68.70 \\
\hline \multicolumn{6}{|l|}{ PB2B-P } \\
\hline \multirow[t]{2}{*}{ S-53 } & $p_{i}^{p}$ & 388.49 & 181.04 & 371.65 & 145.03 \\
\hline & $p_{i}^{e}$ & 319.93 & 163.72 & 323.04 & 128.82 \\
\hline \multicolumn{6}{|l|}{ PB1M-S } \\
\hline \multirow[t]{2}{*}{ S-61 } & $p_{i}^{p}$ & 567.55 & 243.90 & 527.99 & 170.10 \\
\hline & $p_{i}^{e}$ & 419.30 & 206.42 & 428.90 & 131.23 \\
\hline \multirow[t]{2}{*}{ S-62 } & $p_{i}^{p}$ & 625.33 & 223.57 & 567.73 & 225.41 \\
\hline & $p_{i}^{e}$ & 482.61 & 186.76 & 428.91 & 152.36 \\
\hline
\end{tabular}


Table 4 (cont): Observed price averages $(\mathrm{Av})$ and standard deviations (SD) (rounds 1 to 25 and rounds 26 to 50)

\begin{tabular}{lccccc}
\hline PB1M-P & & & & & \\
\hline S-63 & $p_{i}^{p}$ & 514.97 & 217.38 & 491.64 & 208.24 \\
& $p_{i}^{e}$ & 407.23 & 195.36 & 380.78 & 140.64 \\
\hline PB1B-S & & & & & \\
\hline S-71 & $p_{i}^{p}$ & 479.11 & 237.55 & 473.28 & 210.26 \\
& $p_{i}^{e}$ & 357.08 & 178.50 & 353.32 & 132.01 \\
S-72 & $p_{i}^{p}$ & 520.20 & 185.72 & 515.72 & 183.14 \\
& $p_{i}^{e}$ & 419.55 & 144.88 & 395.95 & 124.43 \\
\hline PB1B-P & & & & & \\
\hline S-73 & $p_{i}^{p}$ & 452.74 & 206.8 & 448.30 & 185.63 \\
& $p_{i}^{e}$ & 390.94 & 169.97 & 365.47 & 132.33 \\
\hline \hline
\end{tabular}


Table 5: Price differentials for effective prices

\begin{tabular}{cc}
\hline \hline & Effective prices \\
\hline Constant & 289.10 \\
& $(0.000)$ \\
$D_{P M B}\left(\Delta_{\mathrm{S}}^{P M G-B / B S L}\right)$ & 74.79 \\
$D_{P M M}\left(\Delta_{\mathrm{S}}^{P M G-M / B S L}\right)$ & $(0.000)$ \\
$D_{P B 1 B}\left(\Delta_{\mathrm{S}}^{P B 1 G-B / B S L}\right)$ & 90.90 \\
$D_{P B 1 M}\left(\Delta_{\mathrm{S}}^{P B 1 G-M / B S L}\right)$ & $(0.000)$ \\
$D_{P B 2 B}\left(\Delta_{\mathrm{S}}^{P B 2 G-B / B S L}\right)$ & $(0.000)$ \\
$D_{P B 2 M}\left(\Delta_{\mathrm{S}}^{P B 2 G-M / B S L}\right)$ & 139.81 \\
$D_{p}\left(\Delta_{\mathrm{S}}^{B S L-P / B S L-S}\right)$ & $(0.000)$ \\
$D_{p} D_{P B 1 B}$ & -12.71 \\
& $(0.290)$ \\
$D_{p} D_{P B 1 M}$ & -16.32 \\
$D_{p} D_{P B 2 B}$ & $(0.175)$ \\
$D_{p} D_{P B 2 M}$ & 42.22 \\
& $(0.004)$ \\
Number of obs & -51.38 \\
$\mathrm{R}^{2}$ & $(0.014)$ \\
\hline Note: $\mathrm{p}-\mathrm{values}$ in parentheses. & -90.35 \\
\hline \hline
\end{tabular}


Table 6. Comparison of average effective prices to the BNE and CS (BNE PRICE=310; CS PRICE=380)

\begin{tabular}{lrrrrr}
\hline \hline & & \multicolumn{3}{c}{ Comparison BNE } & \multicolumn{3}{c}{ Comparison CS } \\
& Average & $\chi^{2}(1)$ & p-value & $\chi^{2}(1)$ & p-value \\
\hline BSL-S & 289.10 & 71.40 & 0.000 & 1350.52 & 0.000 \\
PMB-S & 363.89 & 40.20 & 0.000 & 3.59 & 0.058 \\
PMM-S & 380.00 & 64.06 & 0.000 & 0.00 & 0.999 \\
PB1B-S & 374.63 & 57.82 & 0.000 & 0.40 & 0.528 \\
PB1M-S & 428.91 & 195.70 & 0.000 & 33.11 & 0.000 \\
PB2B-S & 276.39 & 15.63 & 0.000 & 148.58 & 0.000 \\
PB2M-S & 272.78 & 19.18 & 0.000 & 159.13 & 0.000 \\
BSL-P & 331.32 & 3.15 & 0.076 & 16.40 & 0.000 \\
PB1B-P & 365.47 & 21.30 & 0.000 & 1.46 & 0.227 \\
PB1M-P & 380.78 & 34.67 & 0.000 & 0.00 & 0.948 \\
PB2B-P & 323.04 & 1.18 & 0.278 & 6.30 & 0.012 \\
PB2M-P & 340.18 & 6.30 & 0.012 & 10.97 & 0.000 \\
\hline \hline
\end{tabular}


Table 7: PG adoption and prices

\begin{tabular}{ccc|cc|cc}
\hline \hline & \multicolumn{2}{c|}{ PMG } & \multicolumn{2}{c|}{ PB1G } & \multicolumn{2}{c}{ PB2G } \\
\cline { 2 - 7 } & $\begin{array}{c}\text { Posted } \\
\text { prices }\end{array}$ & Profits & $\begin{array}{c}\text { Posted } \\
\text { prices }\end{array}$ & Profits & $\begin{array}{c}\text { Posted } \\
\text { prices }\end{array}$ & Profits \\
\hline Constant & 350.76 & 117771 & 337.75 & 108600 & 300.37 & 108614 \\
& $(0.000)$ & $(0.000)$ & $(0.000)$ & & $(0.000)$ & $(0.000)$ \\
$D_{A}\left(\Delta_{S}^{A}\right)$ & 65.09 & 3303 & 190.63 & -3419 & 3.71 & -3995 \\
& $(0.000)$ & $(0.000)$ & $(0.000)$ & $(0.152)$ & $(0.605)$ & $(0.046)$ \\
$D_{P}$ & & & 30.56 & -2830 & 14.87 & 3204 \\
& & & $(0.433)$ & $(0.420)$ & $(0.361)$ & $(0.385)$ \\
$D_{A} D_{P}$ & & & -83.18 & 3501 & 106.65 & -18573 \\
& & & $(0.002)$ & $(0.366)$ & $(0.000)$ & $(0.000)$ \\
\hline Number of & 900 & 900 & 1350 & 1350 & 1350 & 1350 \\
obs & & & & & & \\
\hline $\mathrm{R}^{2}$ & 5.27 & 4.84 & 14.28 & 3.12 & 29.59 & 7.70 \\
\hline \hline
\end{tabular}

Note: $\mathrm{p}$-values in parentheses. 
Appendix

Table A1: Obtaining estimated average prices after equation (5)

\begin{tabular}{ll}
\hline \hline & Estimated average price \\
\hline BSL-S & $\beta_{0}$ \\
PMB-S & $\beta_{0}+\beta_{1}$ \\
PMM-R & $\beta_{0}+\beta_{2}$ \\
PB1B-S & $\beta_{0}+\beta_{3}$ \\
PB1M-S & $\beta_{0}+\beta_{4}$ \\
PB2B-S & $\beta_{0}+\beta_{5}$ \\
PB2M-S & $\beta_{0}+\beta_{6}$ \\
BSL-P & $\beta_{0}+\beta_{7}$ \\
PB1B-S & $\beta_{0}+\beta_{3}+\beta_{7}+\beta_{8}$ \\
PB1M-P & $\beta_{0}+\beta_{4}+\beta_{7}+\beta_{9}$ \\
PB2B-P & $\beta_{0}+\beta_{5}+\beta_{7}+\beta_{10}$ \\
PB2M-P & $\beta_{0}+\beta_{6}+\beta_{7}+\beta_{11}$ \\
\hline \hline
\end{tabular}

